DO NOT RENT

NBSIR 77-1231

\title{
Measurement of Transistor Collector-Emitter Saturation Voltage
}

K. O. Leedy

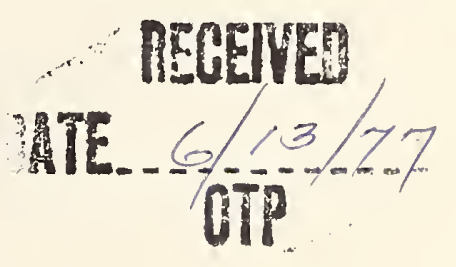

Electronic Technology Division Institute for Applied Technology National Bureau of Standards

Washington, D.C. 20234

June 1977

Final

Prepared for

Defense Nuclear Agency

Washington, D.C. 20305 



\section{MEASUREMENT OF TRANSISTOR COLLECTOR-EMITTER SATURATION VOLTAGE}

K. O. Leedy

Electronic Technology Division Institute for Applied Technology National Bureau of Standards

Washington, D.C. 20234

June 1977

Final

Prepared for

Defense Nuclear Agency

Washington, D.C. 20305

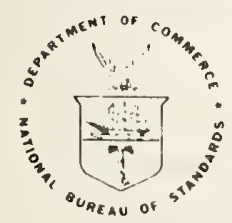

U.S. DEPARTMENT OF COMMERCE, Juanita M. Kreps, Secretary

Dr. Sidney Harman, Under Secretary

Jordan J. Baruch, Assistant Secretary for Science and Technology

NATIONAL BUREAU OF STANDARDS, Ernest Ambler, Acting Director 
Abstract

Introduction

Definition of Saturation

Measurement Method

Temperature Effects

Current Effects

Other Important Parameters

Summary

Acknowledgment

References

Appendix

Distribution

\section{LIST OF FIGURES}

Page

1. Illustration of the three transistor operating regions: cut-off, active, and saturation . . . . . . . . . 2

2a. Collector-emitter voltage as a function of temperature for each of the three 2 N2222 transistors . . . . . . . . . 6

2b. Collector-emitter voltage as a function of temperature for each of the three 2N3055 transistors . . . . . . . . . 7

2c. Collector-emitter voltage as a function of temperature for each of the three 2 N5840 transistors . . . . . . . . 8

3. Typical change in collector-emitter voltage as a function of temperature for the three device types with the data averaged for the three samples of each type . . . . . . . 9

4a. Collector-emitter voltage as a function of duty cycle for each of the three 2 N5840 transistors . . . . . . . . . . . 11 
4b. Typical change in collector-emitter voltage as a function of duty cycle averaged for the three 2N5840 transistors . . . . 12

5a. Collector-emitter voltage as a function of collector current with a fixed base current of $15 \mathrm{~mA}$ for each of the three 2N2222 transistors . . . . . . . . . . . . . . . 14

5b. Collector-emitter voltage as a function of collector current with a fixed base current of $400 \mathrm{~mA}$ for each of the three 2N3055 transistors . . . . . . . . . . . . . . 15

5c. Collector-emitter voltage as a function of collector current with a fixed base current of $200 \mathrm{~mA}$ for each of the three 2N5840 transistors . . . . . . . . . . . . . . . . . . . 16

6. Typical change in collector-emitter voltage as a function of change in collector current . . . . . . . . . . . . . 17

7a. Collector-emitter voltage as a function of base current with a fixed collector current of $150 \mathrm{~mA}$ for each of the three 2N2222 transistors . . . . . . . . . . . . . . 18

7b. Collector-emitter voltage as a function of base current with a fixed collector current of $4 \mathrm{~A}$ for each of the three 2N3055 transistors . . . . . . . . . . . . . . 19

7c. Collector-emitter voltage as a function of base current with a fixed collector current of $2 \mathrm{~A}$ for each of the three 2N5840 transistors . . . . . . . . . . . . . . . . . 20

8. Typical change in collector-emitter voltage as a function of change in base current . . . . . . . . . . . . . . . 21

9a. Collector-emitter voltage as a function of collector current for different values of forced $\beta$ for a 2 N2222 transistor . . . 23

9b. Collector-emitter voltage as a function of collector current for different values of forced $\beta$ for a 2 N3055 transistor . . . 24

9c. Collector-emitter voltage as a function of collector current for different values of forced $\beta$ for a 2 N5840 transistor . . . 25

10. Illustration of Kelvin connections . . . . . . . . . . . 26 


\title{
Measurement of Transistor \\ Collector-Emitter Saturation Voltage
}

\author{
K. O. Leedy \\ Institute for Applied Technology \\ National Bureau of Standards \\ Washington, D. C. 20234
}

\section{ABSTRACT}

This report presents a detailed method for the measurement of collector-emitter saturation voltage. The method which is included in the Appendix is proposed for standardization. The report also contains a description of the laboratory confirmation of the method and a discussion of the precautions to be taken to assure repeatability of the measurement. Emphasized is the necessity to determine that the conditions for saturation are met during the measurement.

\section{INTRODUCTION}

There are three regions of transistor operation: cut-off, active, and saturation. These are illustrated in figure 1 which shows curves of collector current versus collector-emitter voltage for different values of base current. For transistors used in switching applications the cutoff and saturation regions are most important. In saturation, or in the "on" state, an ideal transistor switch should have a very low resistance, approaching that of a short circuit so that the voltage drop across the collector-emitter terminals approaches zero. This voltage drop is called the collector-emitter saturation voltage and is usually represented in specification literature by the symbol $\mathrm{V}_{\mathrm{CE}}$ (SAT)

The saturation voltage is an important parameter because it can be used to predict the performance of a transistor used in switching apparatus such as in $d-c$ to $a-c$ power inverters, chopping circuits, or logic circuits. It represents the "zero" logic level in many types of digital circuits. It is important to know how low the collector-emitter voltage becomes in saturation because during saturation the transistor passes the most current for the longest periods of time, and power dissipation at the collector can become excessive. When a system design is to be used in a radiation environment, it is important to know the change in saturation voltage as a result of radiation dose so that the design can accommodate the changed value.

In the application of a transistor in circuit, it is not always necessary to know the actual $V_{C E}(S A T)$, that is, the collector-emitter voltage of a transistor operating in the saturation region. Instead, it is important to know that for the bias conditions of interest, the collector-emitter voltage is less than a specified value. The circuit designer would have assumed this value, probably from knowledge of 


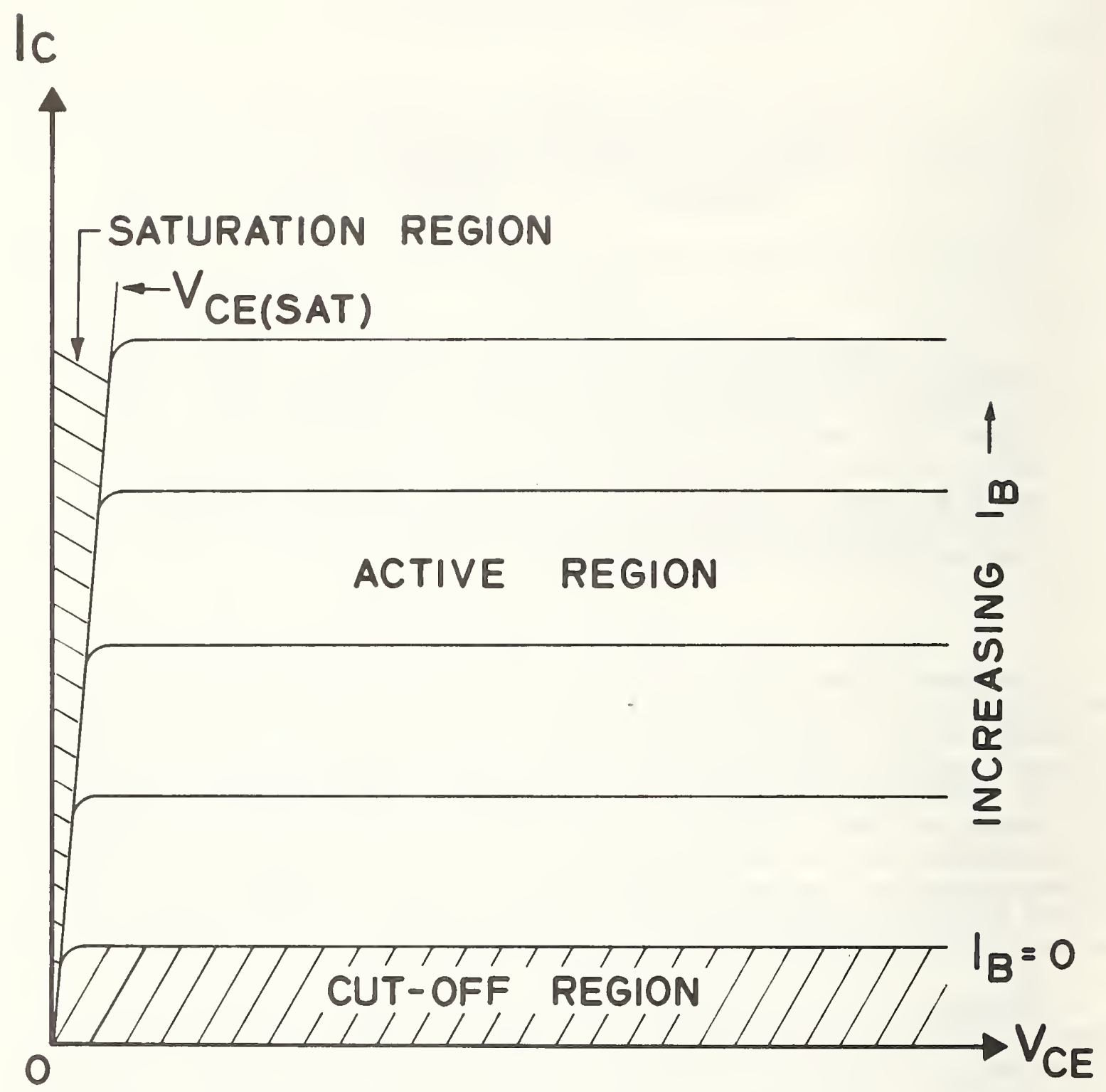

Figure 1. Illustration of the three transistor operating regions: cut-off, active, and saturation. 
$\mathrm{V}_{\mathrm{CE}}$ (SAT) for that transistor type. The mecsurenent method attached c.in be used to determine if a particular transistor will meet the requirement if the test for saturation is omitted.

From the diagram in figure 1 , it is apparent that saturation is a region and that $\mathrm{V}_{\mathrm{CE}}(\mathrm{SAT})$ is not a single point but rather a line. Its value depends on the collector current and base current among other variables. The purpose of the measurement presented here is to adequately define all variables so that a repeatable measurement of $\mathrm{V}_{\mathrm{CE}}$ (SAT) is possible. The method itself is given in the Appendix. It can be used for any $\mathrm{V}_{\mathrm{CE}}$ (SAT) measurement but it is most useful when a measurement of a change in $V_{C E}$ (SAT) is required. Normally, when $V_{C E}$ (SAT) is measured, it is for the purpose of assuring that it be less than a maximum voltage in a specification. This implies that better devices have lower values of $\mathrm{V}_{\mathrm{CE}}$ (SAT) - Therefore, it is to the advantage of the manufacturer to report a low value. To perform his measurement, he then need only control his parameters to the extent that he obtains a measured value of $V_{C E}$ (SAT) low enough to meet the specification. To measure a change in $\mathrm{V}_{\mathrm{CE}}$ (SAT), however, it is necessary to make the measurement twice with all important independent variables specified and carefully controlled.

\section{DEFINITION OF SATURATION}

By definition, ${ }^{l}$ a transistor is operating in the saturation region when both the emitter-base and the collector-base junctions are forwardbiased. The collector-emitter voltage in this condition has two components: the junction saturation voltage, defined below, and the voltages due to the collector saturation current in the collector series resistance and due to the emitter current in the emitter series resistance. The base series resistance can be neglected.

The junction saturation voltage is the difference between the forward-biased junction voltages of the collector-base and the emitterbase junctions. It is given by the Ebers and $\mathrm{Mo}_{1}{ }^{2}$ expression as:

$$
\Delta V_{j}=\frac{k T}{q} \ln \frac{\alpha_{I}\left[1-\frac{I_{C}}{I_{B}} \frac{1-\alpha_{N}}{\alpha_{N}}\right]}{1+\frac{I_{C}}{I_{B}}\left(1-\alpha_{I}\right)}
$$

where

$$
\begin{aligned}
\Delta \mathrm{V}_{\mathrm{j}}= & \text { junction saturation voltage, } \mathrm{V} \\
\mathrm{T}= & \text { absolute temperature, } \mathrm{K} \\
\alpha_{\mathrm{N}}= & \begin{array}{l}
\text { common base large signal d-c current gain with the emitter } \\
\quad
\end{array} \\
& \text { functioning as an emitter and the collector functioning as a }
\end{aligned}
$$




$$
\begin{aligned}
\alpha_{I}= & \text { common base large signal } \mathrm{d}-\mathrm{c} \text { current gain with the emitter } \\
& \text { functioning as a collector and the collector functioning as } \\
& \text { an emitter } \\
\mathrm{I}_{\mathrm{C}}= & \text { collector current, } \mathrm{A} \\
\mathrm{I}_{\mathrm{B}}= & \text { base current, } \mathrm{A} \\
\mathrm{k}= & \text { Boltzman's constant }\left(1.381 \times 10^{-23} \mathrm{~J} / \mathrm{K}\right) \\
\mathrm{q}= & \text { charge on electron }\left(1.602 \times 10^{-19} \mathrm{C}\right) .
\end{aligned}
$$

The saturation voltage is then given by

$$
V_{C E(S A T)}=\Delta V_{j}+I_{C}{ }^{r} C+I_{E} r_{E}
$$

where

$$
\begin{aligned}
& r_{C}=\text { collector series resistance, } \Omega \\
& r_{E}=\text { emitter series resistance, } \Omega .
\end{aligned}
$$

The junction saturation voltage is normally small and rather insensitive to variations in collector or base current because of the logarithmic relation. Of more significance, particularly for power transistors, is the saturation voltage due to the resistive component. The collector region of many power transistors is lightly doped to obtain high breakdown voltages and the transistor is usually operated at high currents in saturation. Under conditions which affect $V_{C E}(S A T)$, such as an increase in temperature or an exposure to radiation, the effect on the collector resistance can produce a major change in $V_{C E}(\mathrm{SAT})$, as can the effects of variations in transistor gain.

\section{MEASUREMENT METHOD}

The method for measuring $\mathrm{V}_{\mathrm{CE}}(\mathrm{SAT})$ as outlined in the Appendix requires that the following measurement conditions be specified:

1) $\mathrm{I}_{\mathrm{C}}$ - the collector current

2) $I_{B}$ - the base current

3) ambient temperature

4) selection of a pulsed or $d-c$ method, and

5) the pulse width and duty cycle (if other than $300 \mu$ s and $2 \%$, respectively).

This information must be included in the specification for $\mathrm{V}_{\mathrm{CE}}$ (SAT) for the particular device to be tested, such as in the detailed specifi- 
cation in the appropriate military standard, if the specification is to be meaningful. The method instructs the user how to determine all circuit values. It describes all necessary apparatus, procedural steps to be performed, data to be taken, and cautions to be observed.

Using this method, several experiments were performed to determine the sensitivity of the measured $V_{C E}$ (SAT) to several variables. Three transistor types were chosen for these experiments: a small-signal transistor (2N2222), a single-diffused power transistor (2N3055), and a triple-diffused power transistor (2N5840). These devices are found in military systems and each is available in a military version. These device types were selected to provide a wide variation in measured results for variations in the measurement parameters. Three devices of each type were used for each experiment. All were off-the-shelf commercial transistors. Though the number of devices used is small, the data indicate the trends in the effects of the variables and, as such, indicate which parameters are necessary to control carefully and which are not.

\section{TEMPERATURE EFFECTS}

The value of $\mathrm{V}_{\mathrm{CE}}$ (SAT) is dependent on temperature in at least two ways: first, temperature appears in the expression for the junction saturation voltage, and second, the collector series resistance is a function of temperature. The method specifies that the measurement be made at a nominal temperature of $20^{\circ} \mathrm{C}$ and that the power levels used do not give rise to significant heating of the junction. To investigate the effects of elevated temperature on the value of $V_{C E}(S A T)$, the following experiments were performed.

To simulate a rise in the ambient temperature, the transistors were placed in a heated oil bath whose temperature was controlled at approximately $10^{\circ} \mathrm{C}$ intervals from room temperature to $100^{\circ} \mathrm{C}$ during measurement of $\mathrm{V}_{\mathrm{CE}}(\mathrm{SAT})$. Sufficient time was allowed for the transistor to reach a steady-state temperature between measurements.

Figure 2 shows the measured value of $\mathrm{V}_{\mathrm{CE}}$ (SAT) versus temperature for the three transistor types studied. In each case the base current was pulsed with a $2 \%$ duty cycle and a pulse width of $300 \mu \mathrm{s}$. Both the 2N2222, figure $2 \mathrm{a}$, and 2N3055, figure $2 \mathrm{~b}$, show a small increase in $\mathrm{V}_{\mathrm{CE}}$ (SAT) with temperature while the $2 \mathrm{~N} 5840$, figure $2 \mathrm{c}$, shows a much greater increase. It is to be expected that the 2 N5840 would be much more sensitive to temperature since it is designed to have a very high breakdown voltage. In order to have a high breakdown voltage, the collector region has a very low doping level which provides a high collector series resistance with a high temperature coefficient. To compare the performance of the three transistor types, the data in figure 2 was plotted in figure 3 as percentage change in $V_{C E}(S A T)$ from its value at room temperature as a function of temperature. In this case the percent change in $\mathrm{V}_{\mathrm{CE}}$ (SAT) is 


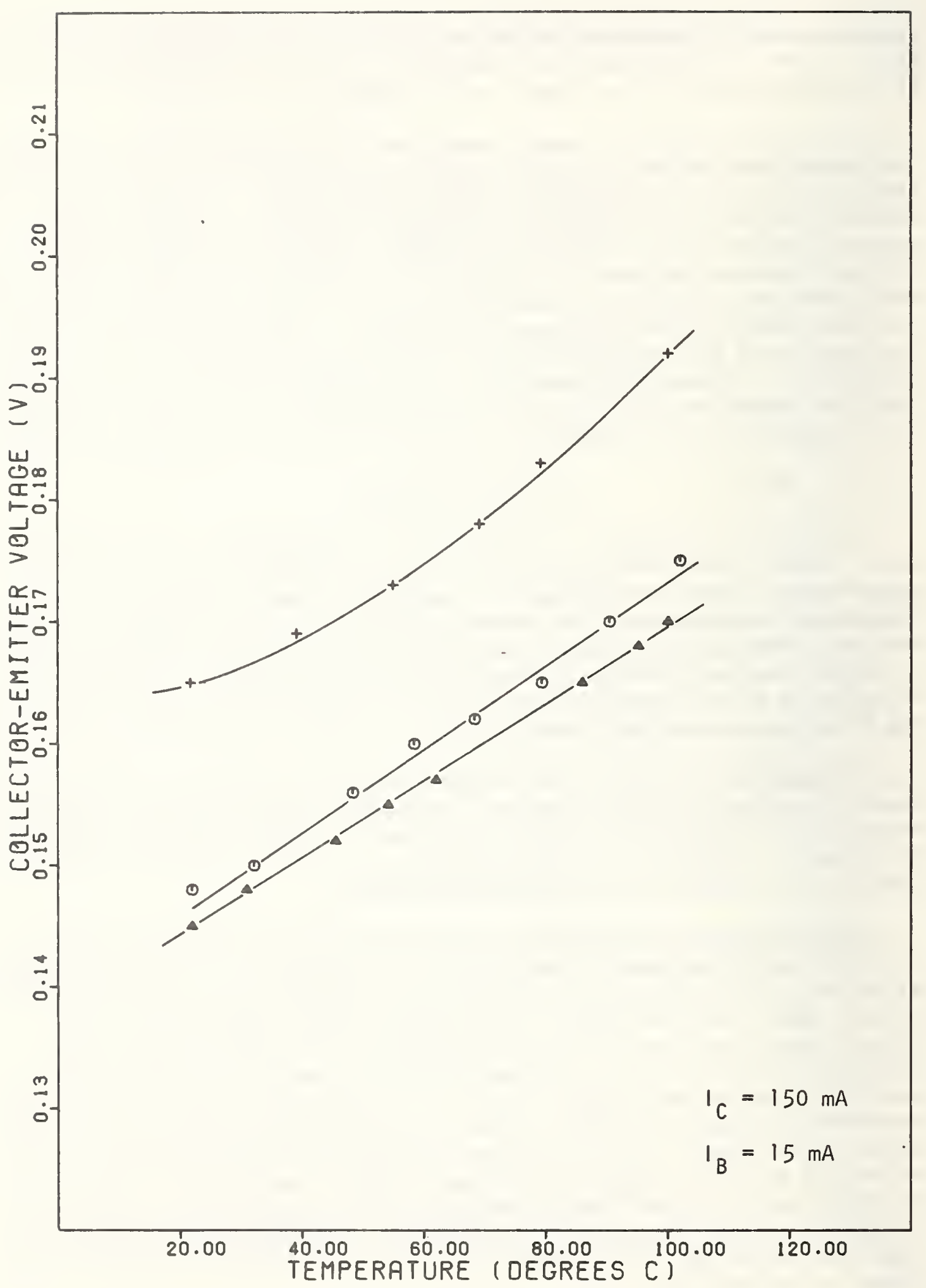

Figure 2a. Collector-emitter voltage as a function of temperature for each of the three 2N2222 transistors. 


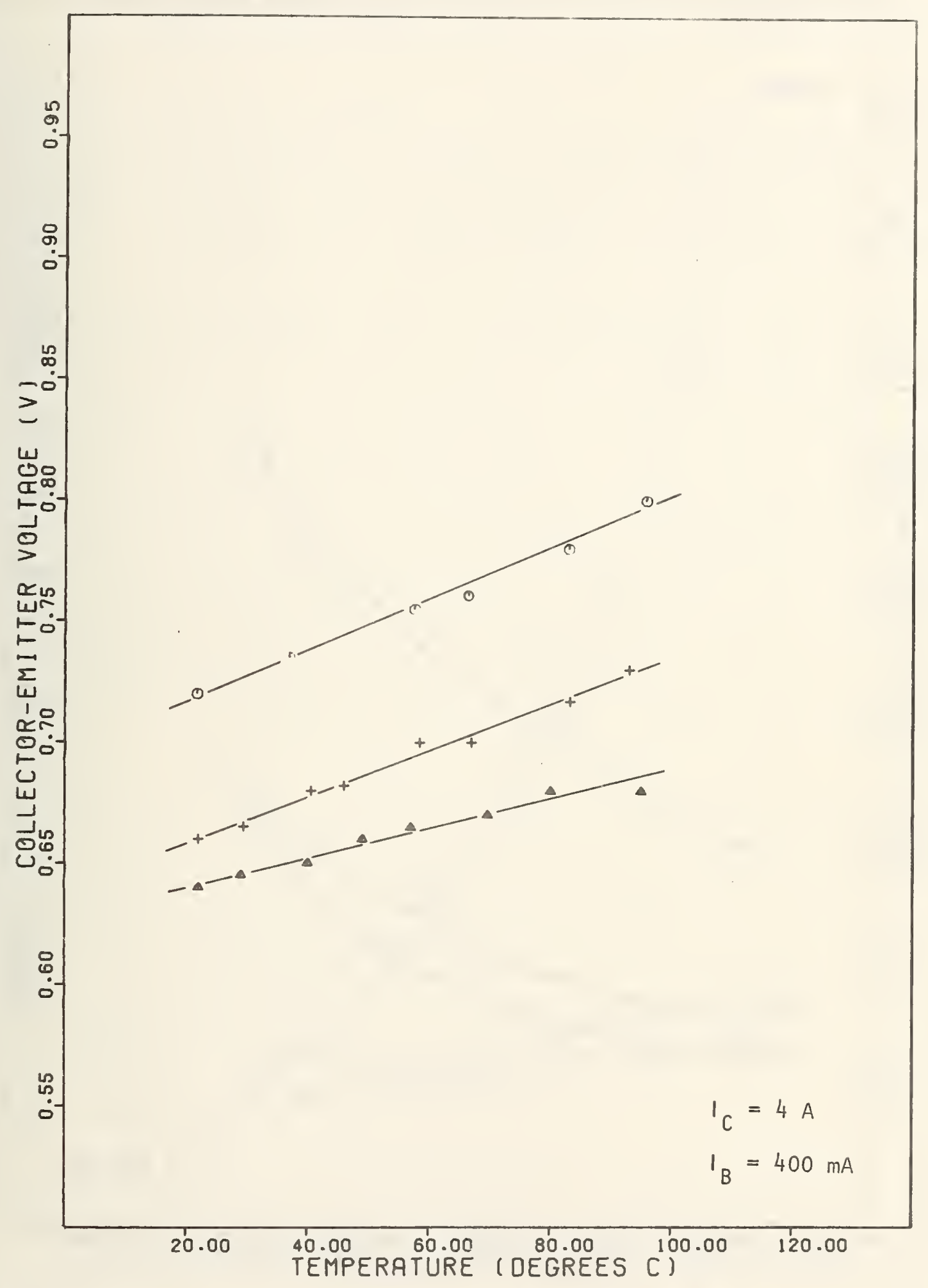

Figure 2b. Collector-emitter voltage as a function of temperature for each of the three 2N3055 transistors. 


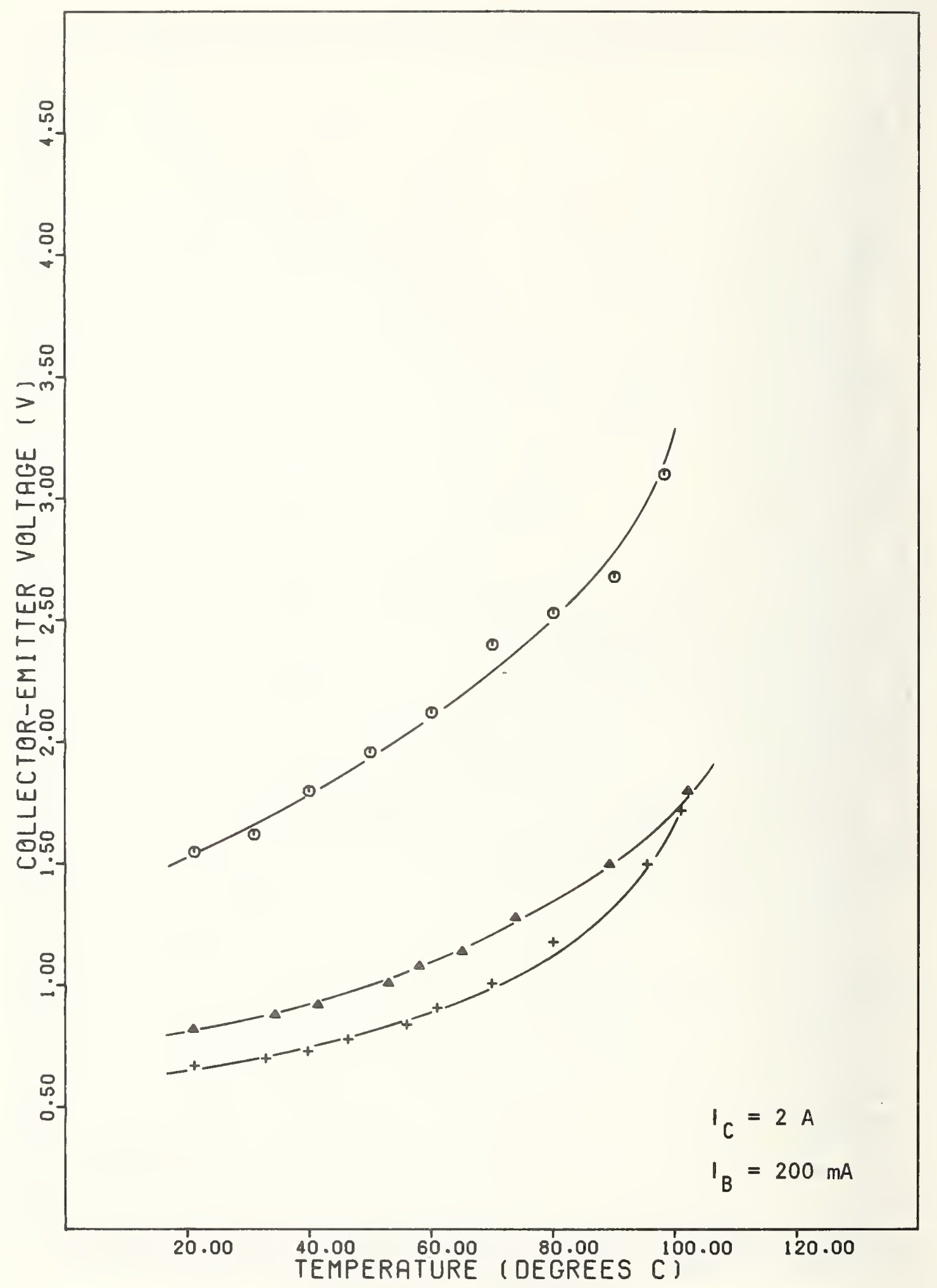

Figure 2c. Collector-emitter voltage as a function of temperature for each of the three 2N5840 transistors. 


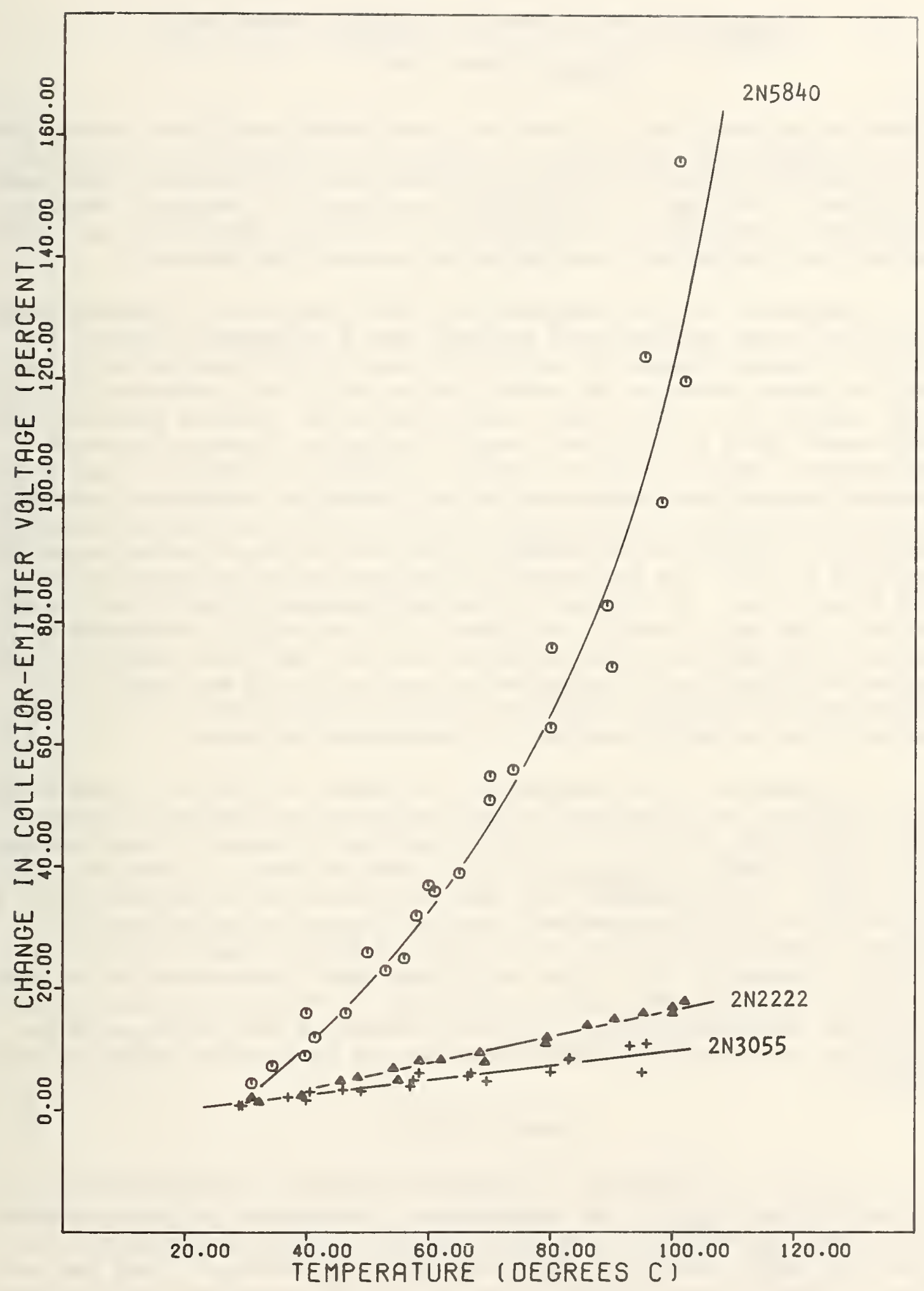

Figure 3. Typical change in collector-emitter voltage as a function of temperature for the three device types with the data averaged for the three samples of each type. 


$\frac{\mathrm{V}_{\mathrm{CE}(\mathrm{SAT})} \text { (Elevated Temp.) }-\mathrm{V}_{\mathrm{CE}} \text { (SAT) (Room Temp.) }}{\mathrm{V}_{\mathrm{CE} \text { (SAT) }} \text { (Room Temp.) }}$

These curves show that for practical measurement conditions, normal laboratory temperature conditions are adequate as deviations of less than $10^{\circ} \mathrm{C}$ result in changes in $\mathrm{V}_{\mathrm{CE}}$ (SAT) of less than $5 \%$. However, with some transistor types when a very precise measurement is required, ambient temperature changes can be significant. For this reason, the method requires that the ambient temperature be measured and recorded.

Examination of the manufacturer's specified value of thermal resistance for these devices would indicate that a temperature rise of two or three degrees Celsius at most would result from junction heating at the low power levels of the saturation region if the transistor is properly mounted with a heat-sink. According to the previous measurements, this would yield very little change in $V_{C E}(S A T)$. However, since the measurement could be made in a condition where the transistor was not properly mounted on a heat-sink, it was decided to determine the effect of junction heating. Also examined was the effect on the measurement of $\mathrm{V}_{\mathrm{CE}}$ (SAT) of errors in the setting of the duty cycle, from the normal value of $2 \%$ to $25 \%$. The duty cycle is the fraction of the cycle in which the pulse is on. It is given by the pulse width divided by the period of the cycle and is usually expressed as a percentage. Since the duty cycle is dependent on both the pulse width and the pulse repetition rate, errors in either can be expressed as an error in the duty cycle. The measurement of $\mathrm{V}_{\mathrm{CE}}$ (SAT) versus duty cycle was made only on the $2 \mathrm{~N} 5840$ since it was the most sensitive to temperature variation.

The results of the measurements are shown in figure 4. Figure 4a shows $V_{C E}$ (SAT) as a function of duty cycle with a fixed pulse width of 300 us for each of the three devices measured. Figure $4 \mathrm{~b}$ shows average percentage change in $\mathrm{V}_{\mathrm{CE}}$ (SAT) for the three devices as a function of duty cycle. It is apparent that the duty cycle can be increased from 2 to 20 percent with the measured value of $V_{C E}$ (SAT) changing only by $5 \%$. Errors in setting the duty cycle or pulse width for small deviations from the nominal $2 \%$ duty cycle and 300- $\mu$ s pulse width would not be significant. However, the method allows that other values be used if required by the specification. If other values of duty cycle and pulse width are to be used, the possible effect of temperature should be considered.

\section{CURRENT EFFECTS}

The effect of both the base and the collector currents on the measured value of $\mathrm{V}_{\mathrm{CE}}$ (SAT) was investigated. Variations in these currents affect the measurement in two ways. First, a change in collector current will alter the $I_{C}{ }_{C}$ term of the saturation voltage. This can produce a change in the measured value of $V_{C E}$ (SAT) approximately proportional to the change in collector current. Second, changing either current can cause the transistor to operate in the active region instead of the saturation region. This will increase the measured value of $V_{C E}$ by sev- 


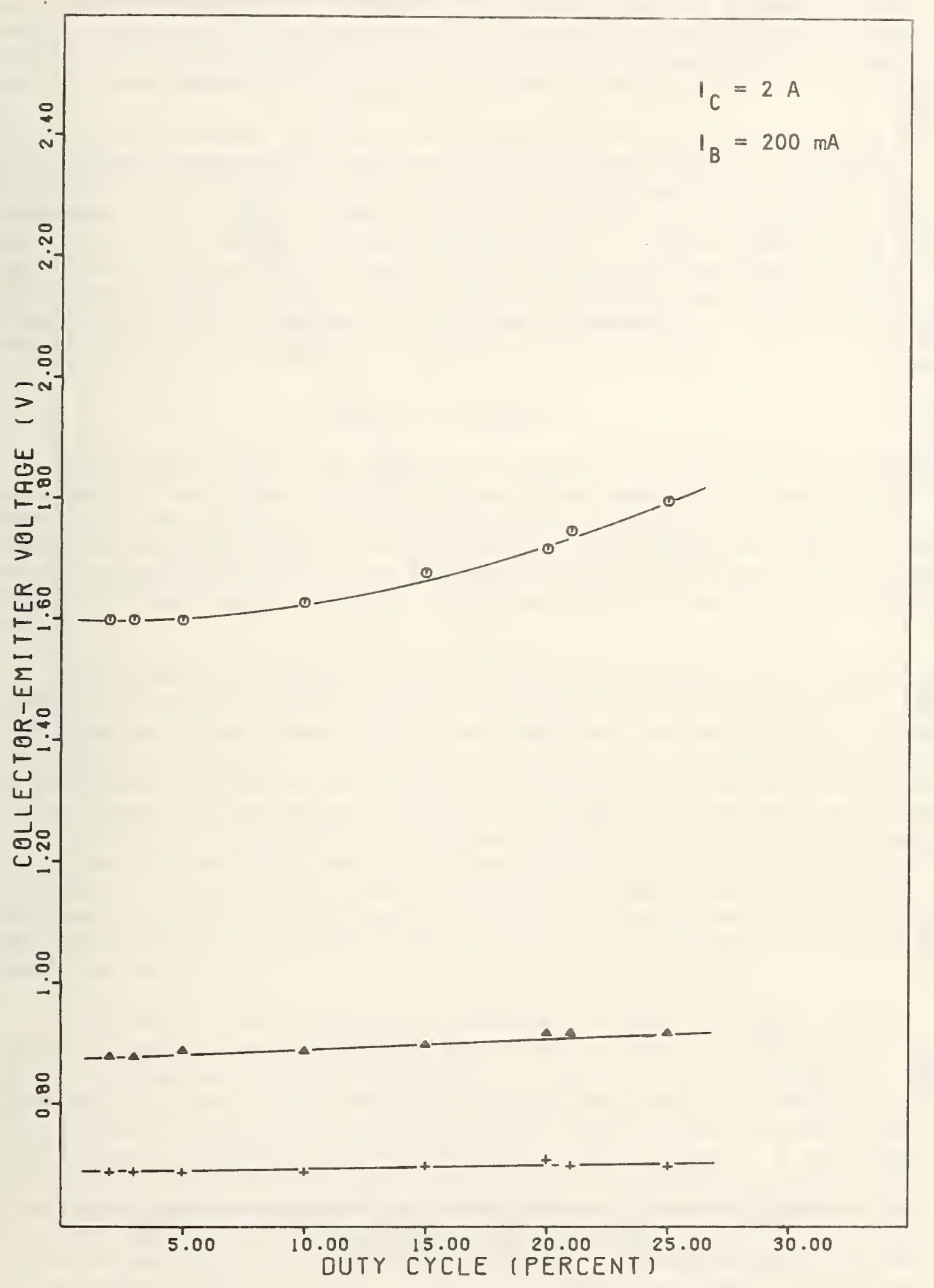

Figure 4a. Collector-emitter voltage as a function of duty cycle for each of the three 2 N5840 transistors. 


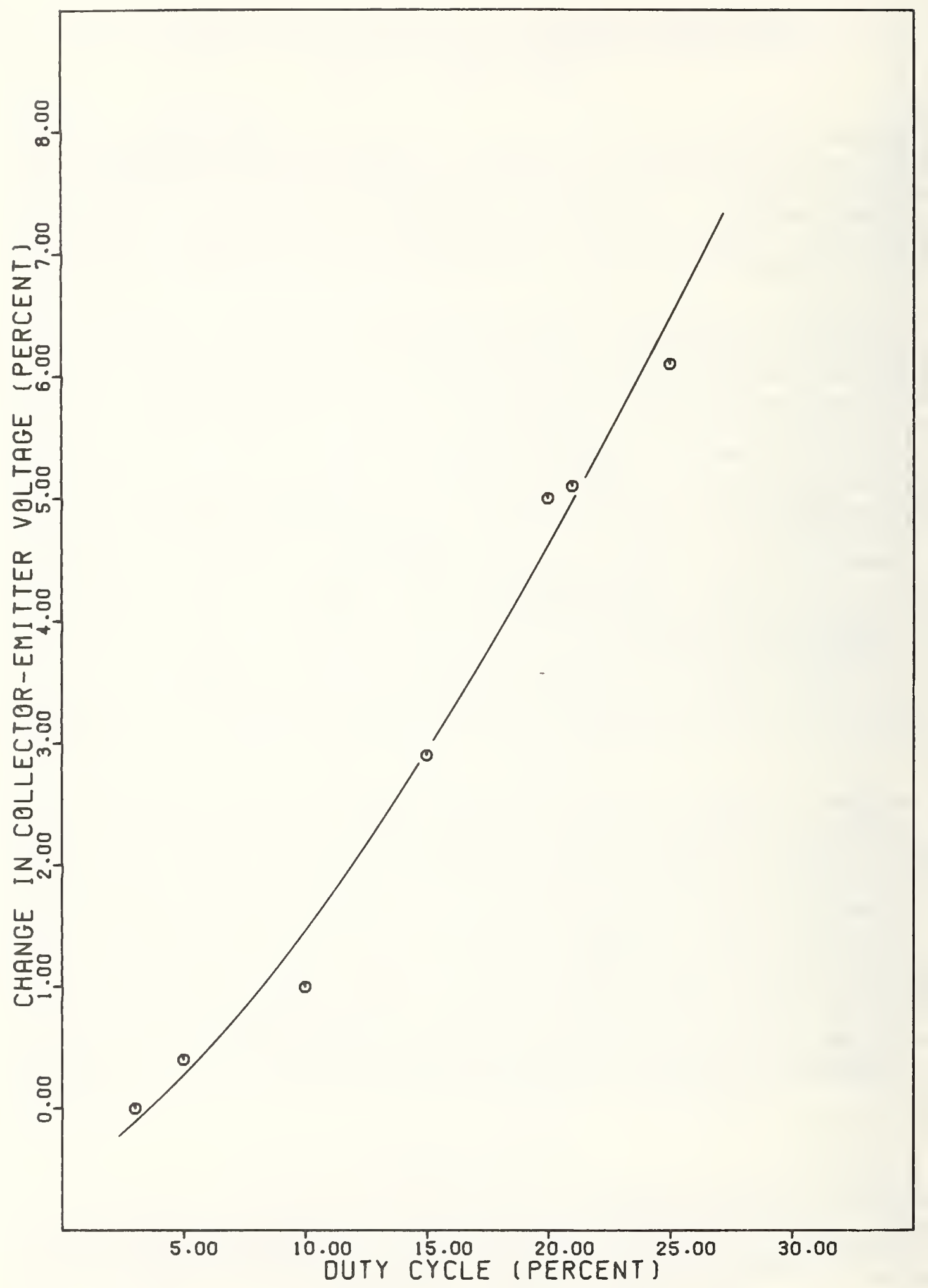

Figure 4b. Typical change in collector-emitter voltage as a function of duty cycle averaged for the three 2 N5840 transistors. 
eral hundred percent for changes in $I_{C}$ of only tens of percent. Obviously, this value of collector-emitter voltage is not $\mathrm{V}_{\mathrm{CE}}$ (SAT). Assuring that the transistor is indeed operating in the saturation region during the measurement of $\mathrm{V}_{\mathrm{CE}}(\mathrm{SAT})$ is of utmost importance.

As was indicated earlier, the definition of saturation is when both the collector-base and the emitter-base junctions are forward-biased. In practice the bias conditions to assure saturation are difficult to determine. It is more convenient to observe the gain to determine saturation. The $d-c$ common emitter current gain, $\beta$, is the ratio of $I_{C}$ to $I_{B}$. When the transistor is operating in the saturation region, this ratio is referred to as the forced gain, since both $I_{C}$ and $I_{B}$ are set in order to force the transistor to operate in saturation. It is convenient to consider a transistor to be in saturation if

$$
\beta_{\text {forced }} \ll \beta_{\text {active }}
$$

Measurements were made of $\mathrm{V}_{\mathrm{CE}}$ as a function of base and collector currents for the three transistor types. The base and collector currents were sensed with a current transformer, the output of which was viewed on an oscilloscope. As outlined in the method, the current could have been measured by using an oscilloscope with a differential input to measure voltage across resistors in series with the base and the collector.

The results of varying $I_{C}$ with $I_{B}$ fixed are shown for the 2 N2222 in figure 5a, for the 2 N3055 in figure 5b, and the 2 N5840 in figure $5 \mathrm{c}$. In each case the value chosen for $I_{B}$ was the value required in the detailed military specification. The value required for $I_{C}$ in that specification is indicated by an arrow in each case. The data are combined in figure 6 which shows the percentage change in $V_{C E}$ versus percentage change in $I_{C}$ for the three transistor types. Each data point represents the average value for the three devices sampled. Similar curves of $V_{C E}$ versus $I_{B}$, with $I_{C}$ constant, are shown in figure 7 . Figure 8 shows the results combined. Again, in each case, the value which was fixed for $I_{C}$ is from the detailed military specification and the $I_{B}$ value required in that specification is noted.

The results show that $V_{C E}$ is sensitive to both $I_{C}$ and $I_{B}$ in most cases. Errors in measuring these currents can result in significant errors in the measured value of $\mathrm{V}_{\mathrm{CE}}$ (SAT). For this reason the method stresses the necessity of making accurate measurements of these currents. The portion of the curves where the slope is very steep represents operation of the transistor in or very near the active region. A measurement of $V_{C E}$ here is not of $V_{C E}$ (SAT). When $I_{B}$ and $I_{C}$ (or the forced $B$ ) are selected in the specification for this method, care should be taken so that this measurement is made well within the saturation region so that errors in setting the currents will not cause the measurement to be made in the active region. For the three transistor types used in this report, the value of forced $\beta$ given in the detailed specification of the military standard is 10 in each case. That is, the $V_{C E}$ (SAT) measurement is made with an $I_{C}$ to $I_{B}$ ratio of 10 . This is the same value chosen for 


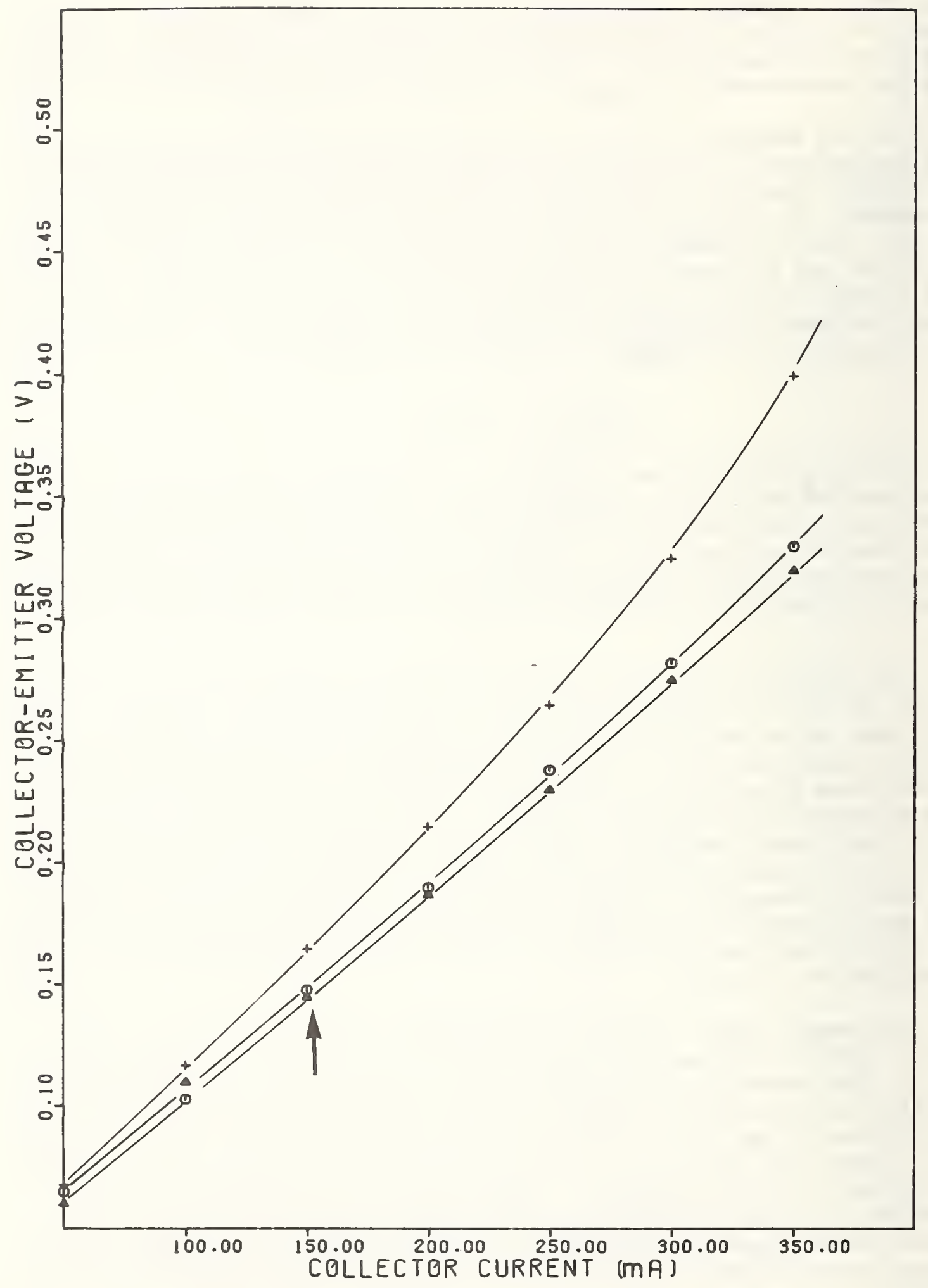

Figure 5a. Collector-emitter voltage as a function of collector current with a fixed base current of $15 \mathrm{~mA}$ for each of the three 2 N2222 transistors. 


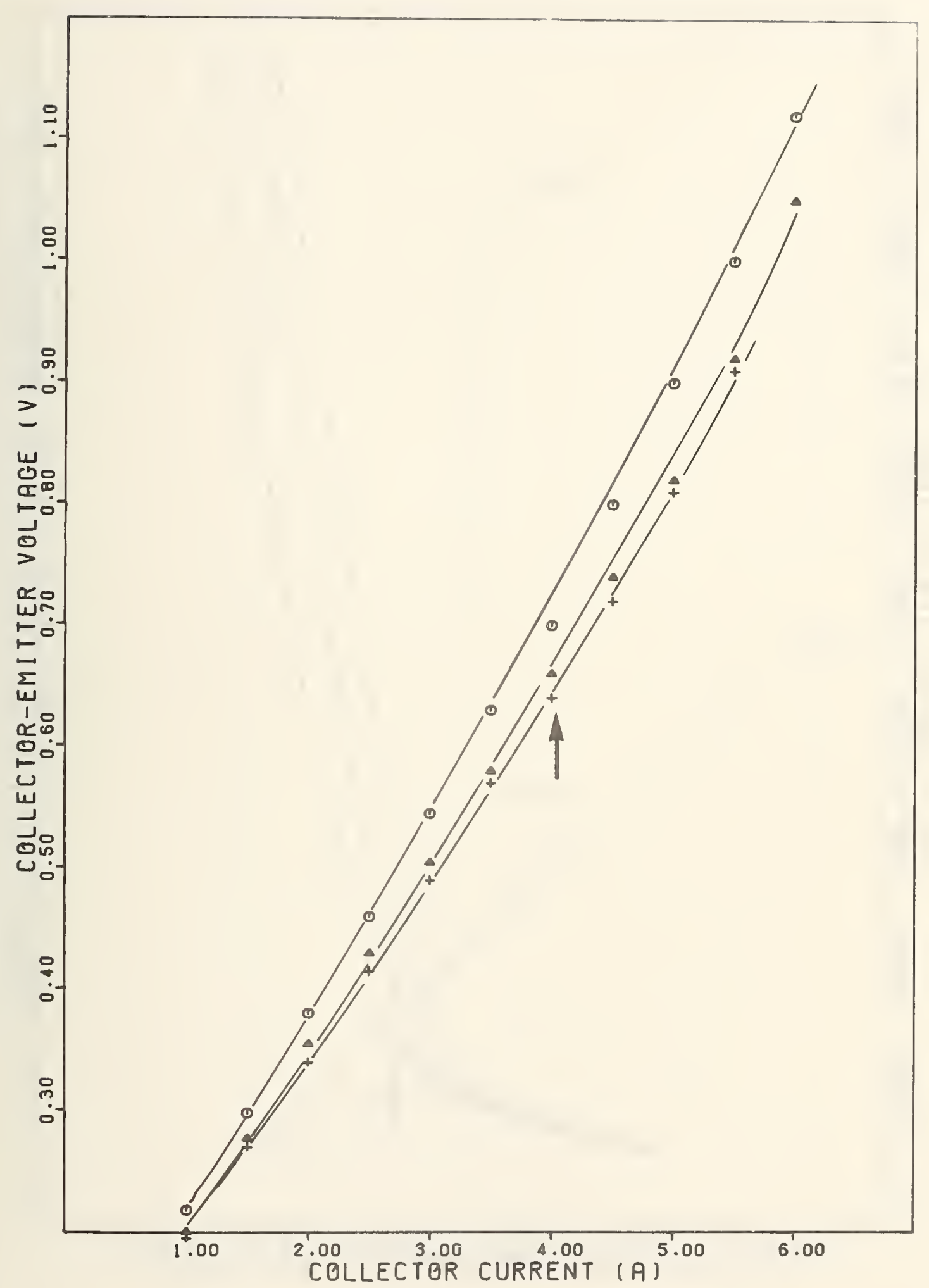

Figure 5b. Collector-emitter voltage as a function of collector current with a fixed base current of $400 \mathrm{~mA}$ for each of the three $2 \mathrm{~N} 3055$ transistors. 


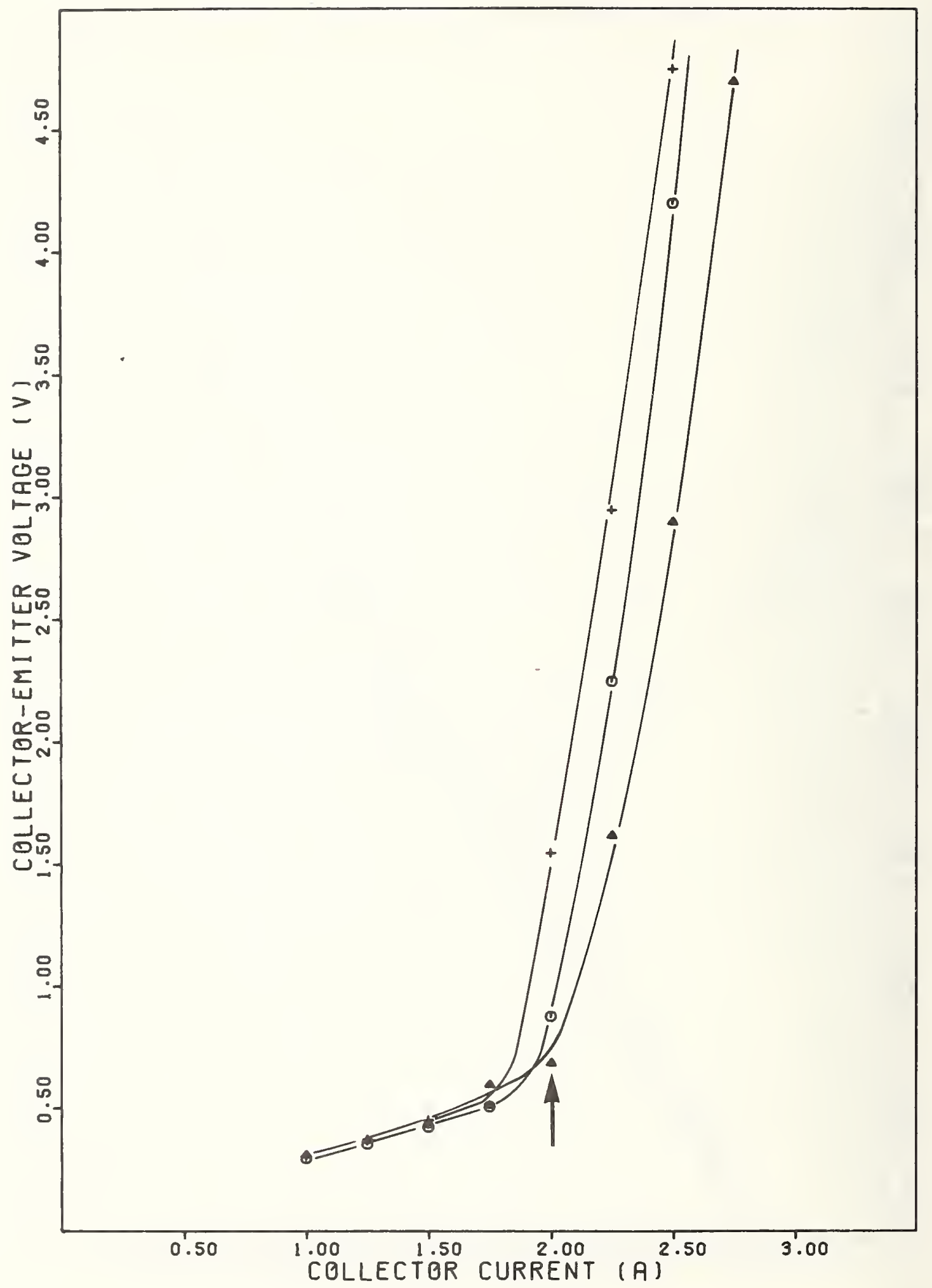

Figure 5c. Collector-emitter voltage as a function of collector current with a fixed base current of $200 \mathrm{~mA}$ for each of the three 2 N5840 transistors. 


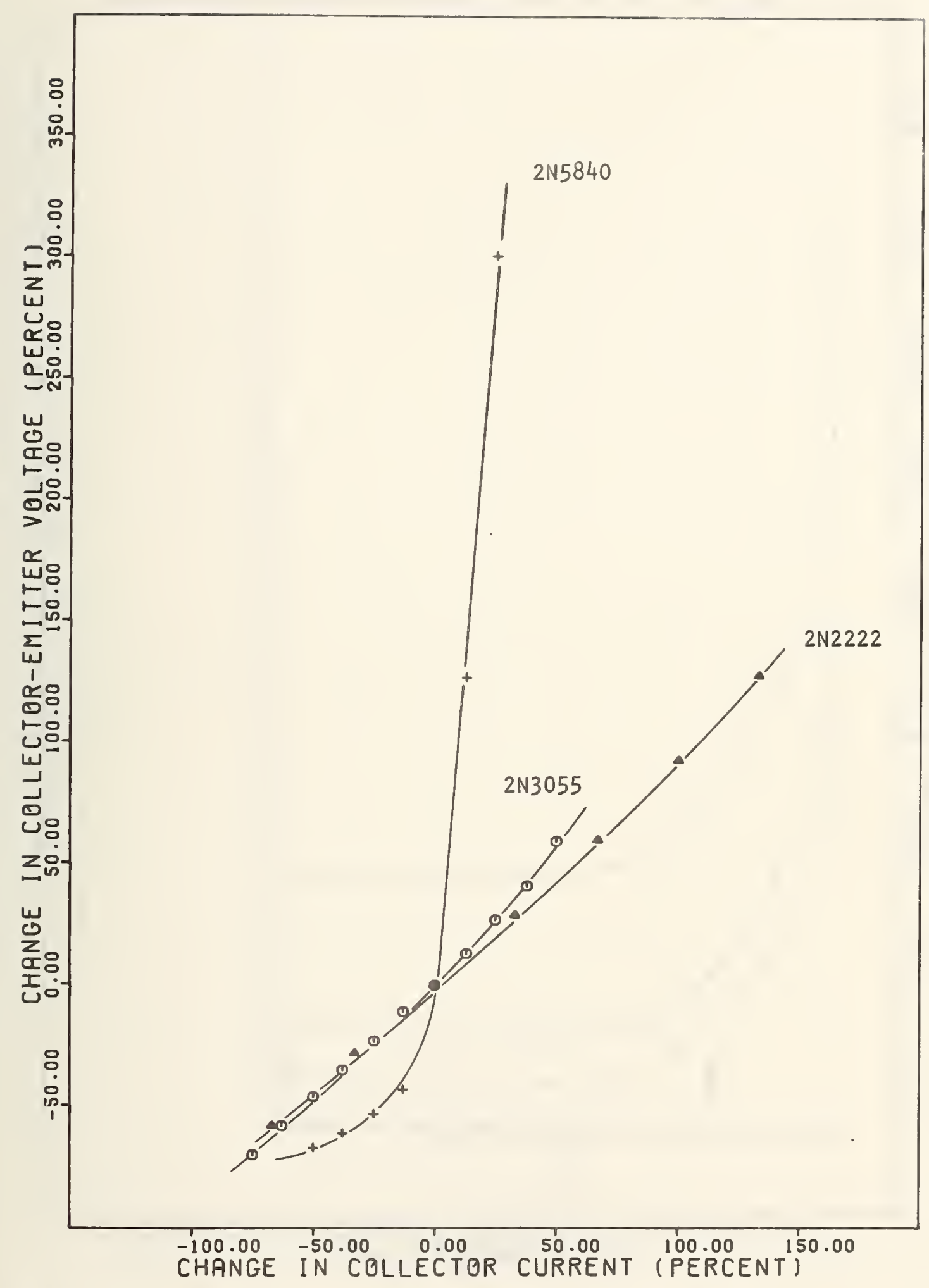

Figure 6. Typical change in collector-emitter voltage as a function of change in collector current. 


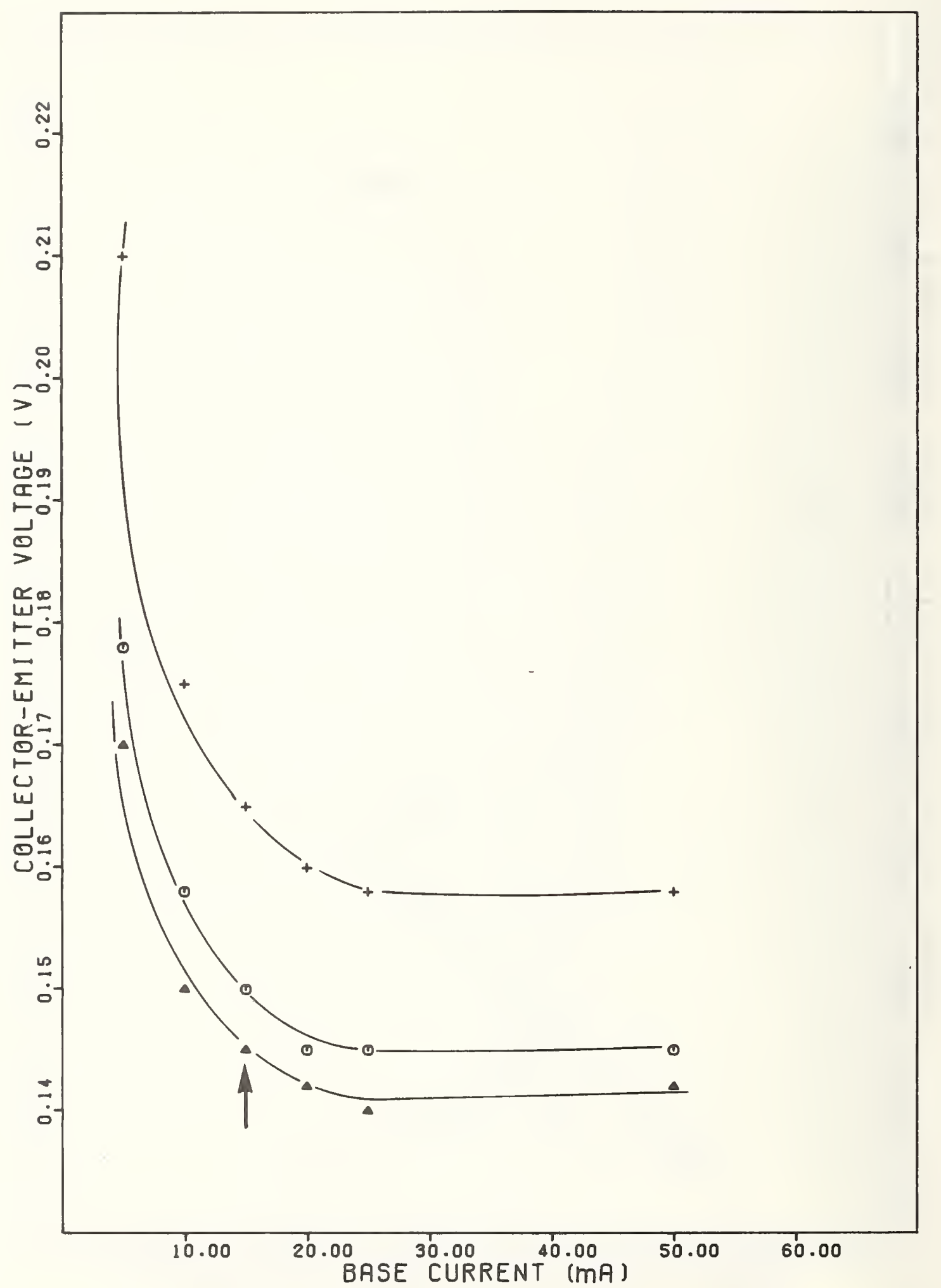

Figure 7a. Collector-emitter voltage as a function of base current with a fixed collector current of $150 \mathrm{~mA}$ for each of the three $2 \mathrm{~N} 2222$ transistors. 


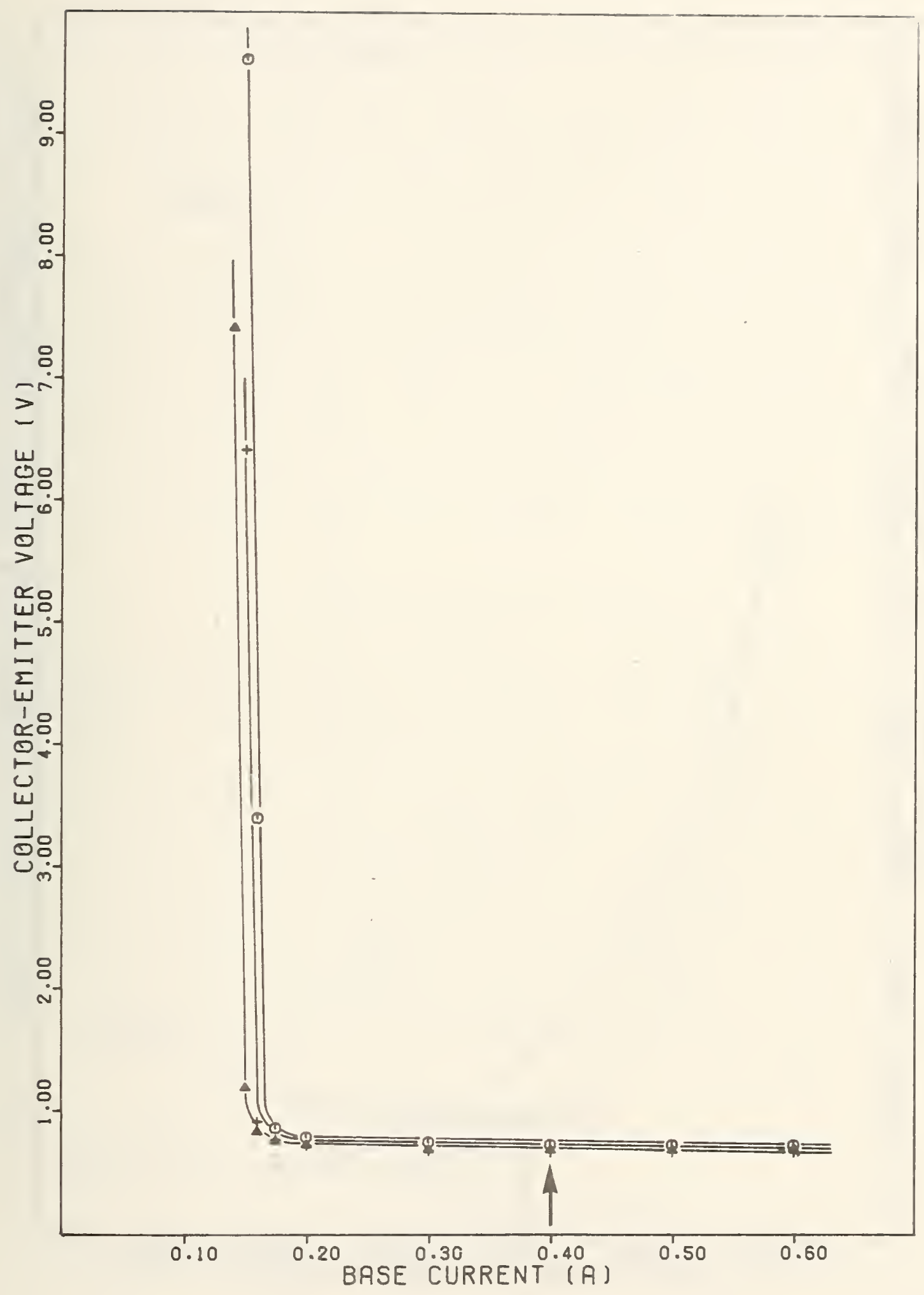

Figure 7b. Collector-emitter voltage as a function of base current with a fixed collector current of $4 \mathrm{~A}$ for each of the three 2 N3055 transistors. 


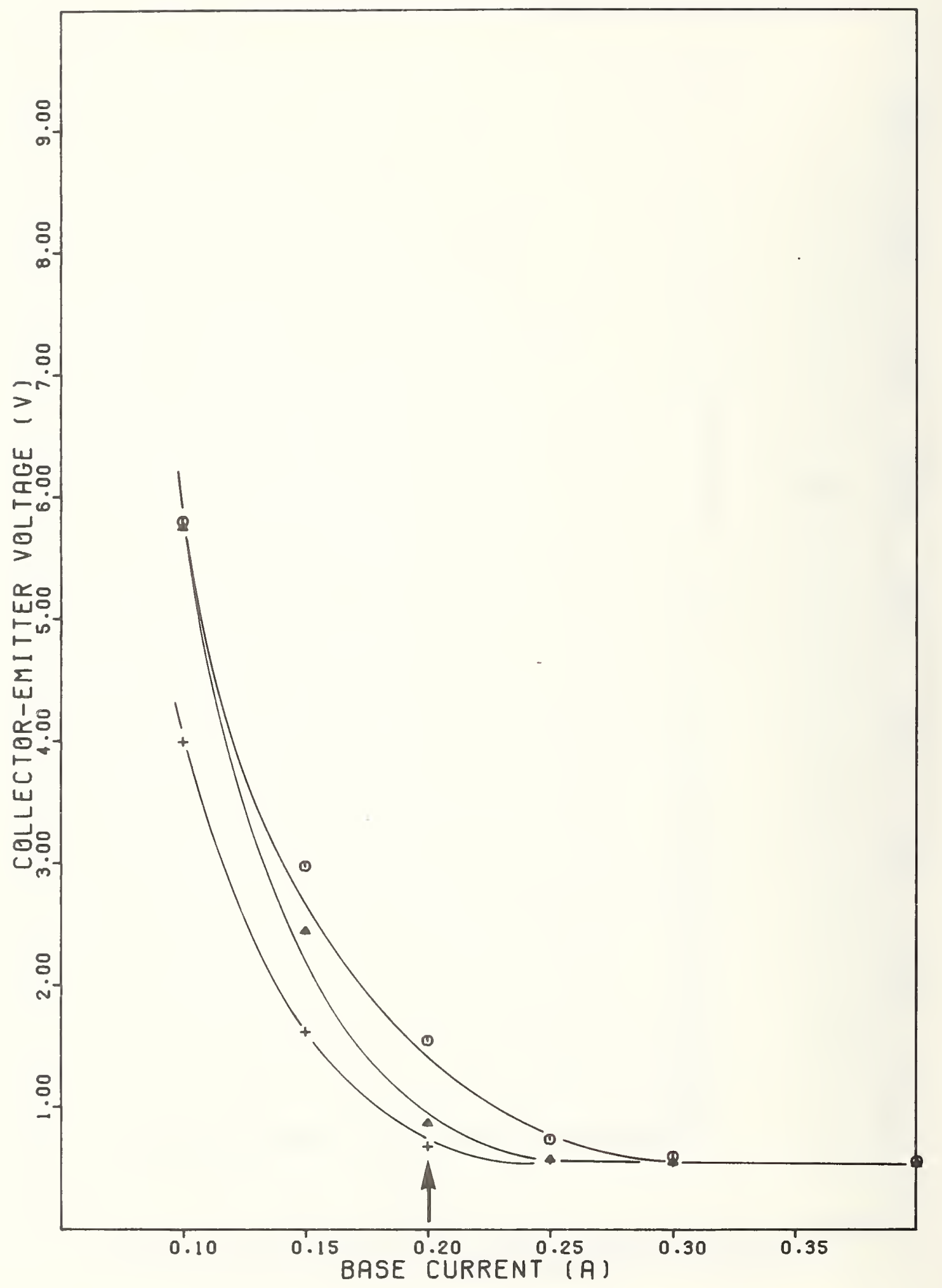

Figure 7c. Collector-emitter voltage as a function of base current with a fixed collector current of $2 \mathrm{~A}$ for each of the three 2 N5840 transistors. 


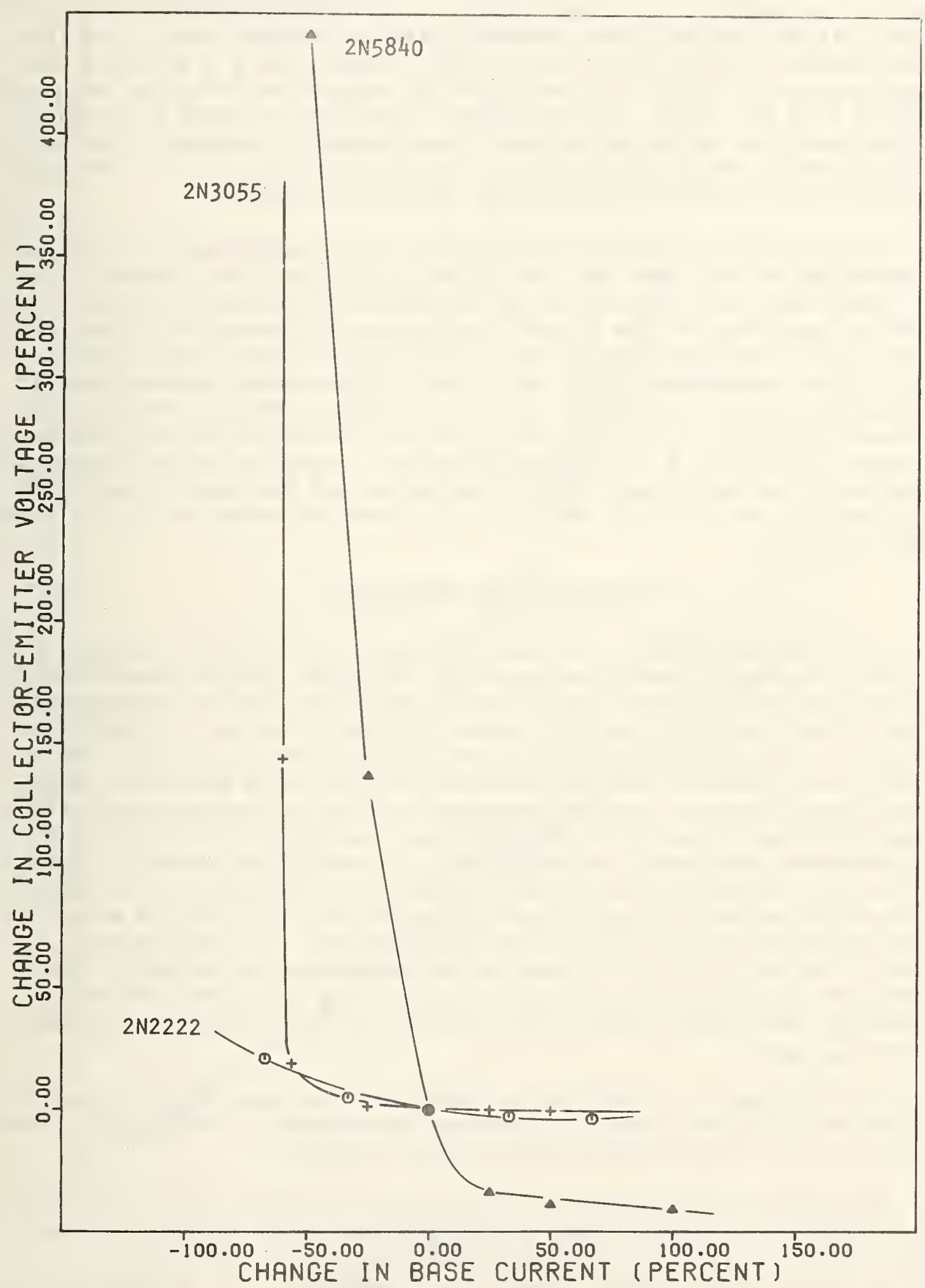

Figure 8. Typical change in collector-emitter voltage as a function of change in base current. 
nearly every transistor for which there is a detailed military specification. It is also the ratio commonly given on manufacturer's specification sheets. In our case, for the 2 N2222 which has a $\beta$ in the active region in excess of 100 , the condition for saturation is easily met with a forced $\beta$ of 10. Also, for the 2N3055, which has a normal $\beta$ of about 50, the condition is satisfied over a wide range of currents. For the 2N5840, however, which has a minimum specified gain of only 10 , using a forced $\beta$ of 10 is operating very near the active region.

To illustrate the effect of forced $\beta$ on the measurement of $\mathrm{V}_{\mathrm{CE}}$ (SAT), an investigation was made into the effect of varying this factor. Figure 9 shows $V_{C E}$ as a function of $I_{C}$ for different values of forced $\beta$. It can be seen that as the forced $\beta$ approaches the normal $\beta$ of the transistor, small variations in $I_{C}$ give increasingly larger variations in $\mathrm{V}_{\mathrm{CE}}$. If the measurement point is on one of these steep curves, precise measurement of $V_{C E}$ is difficult and it is doubtful whether the results represent $V_{C E}(S A T)$. It is not the intent of the method to describe how to choose the forced $\beta$ of the specification. Since it is very important, the method gives guidelines for its selection and outlines a test which can be made to determine if the selection provides operation in the saturation region.

\section{OTHER IMPORTANT PARAMETERS}

There are other practical considerations for measuring $\mathrm{V}_{\mathrm{CE}}$ (SAT) particularly in power transistors where the collector currents used can be many amperes so that even a small series resistance in the voltage measuring circuit can be a serious source of error. The use of Kelvin connections, such as illustrated in figure 10 for a transistor in a TO-3 package, can eliminate most of these series resistance problems. With Kelvin connections the voltage measuring circuit is separated from the current driving circuit. The voltage measurement is made with a very high impedance instrument so that there is a negligible amount of current in that portion of the circuit. There is a separate set of leads to which the current driving circuit is attached. If there is an extraneous resistance in the voltage measuring circuit, the voltage drop across it is negligible. If there is an extraneous resistance in the current driving circuit, the voltage drop across it is not involved in the voltage measurement and therefore will not lead to an error in measuring $\mathrm{V}_{\mathrm{CE} \text { (SAT) }}$.

Note in figure 10 that Kelvin connections are made only to the emitter and collector leads. No voltage measurement is made in the base circuit so that Kelvin connections are not required.

The method requires Kelvin connections to be made on the collector and emitter leads for all types of transistors tested. There are perhaps transistor types which have a high $\mathrm{V}_{\mathrm{CE}}$ (SAT) at a low collector current for which Kelvin connections are not essential. It is difficult to incorporate into the method a means of judging when to use Kelvin connections since the possible size of an extraneous resistance is not known. Since the majority of transistor types require Kelvin connections in any 


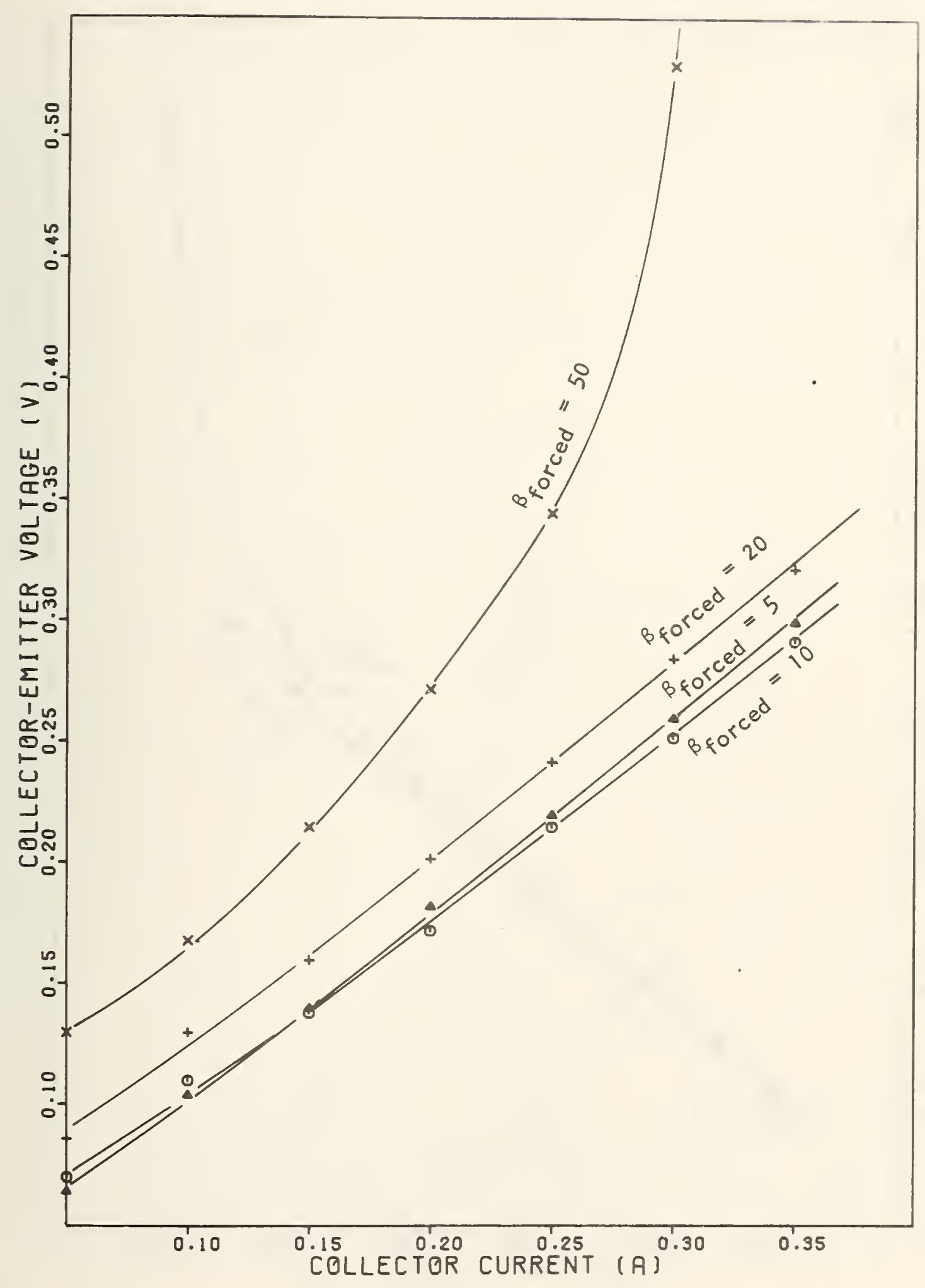

Figure 9a. Collector-emitter voltage as a function of collector current for different values of forced $\beta$ for a $2 \mathrm{~N} 2222$ transistor. 


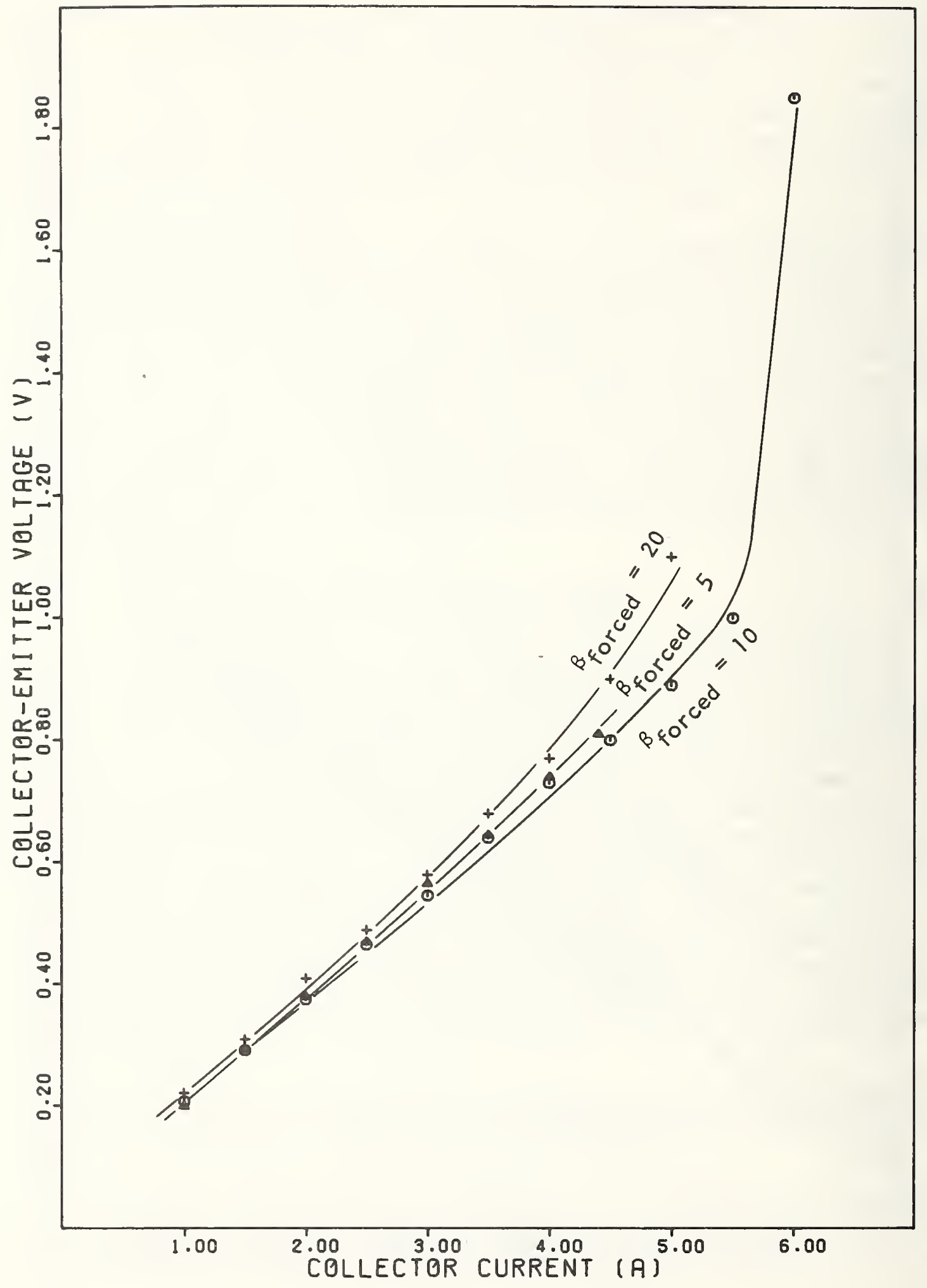

Figure 9b. Collector-emitter voltage as a function of collector current for different values of forced $B$ for a 2 N3055 transistor. 


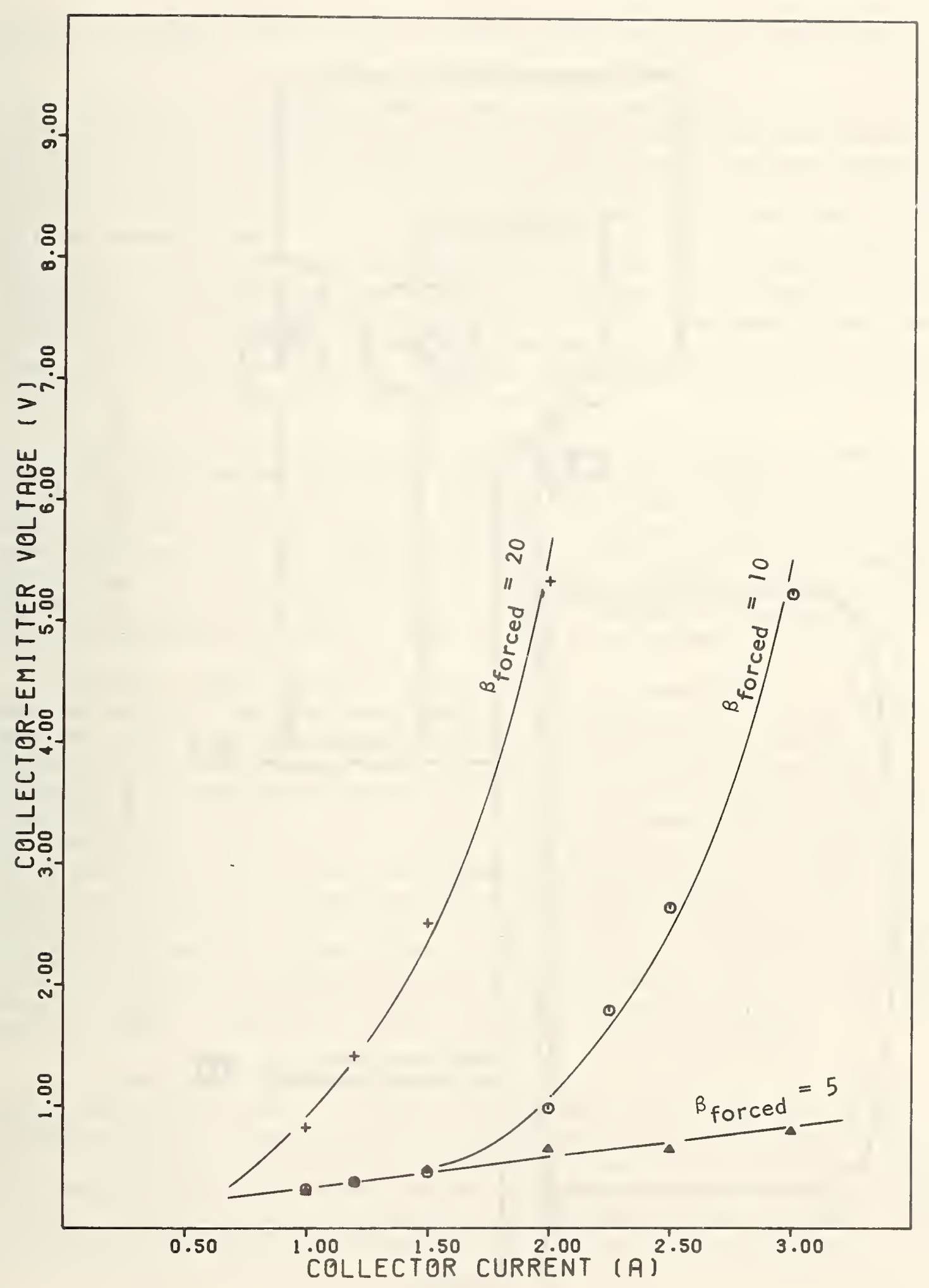

Figure 9c. Collector-emitter voltage as a function of collector current for different values of forced $\beta$ for a 2N5840 transistor. 


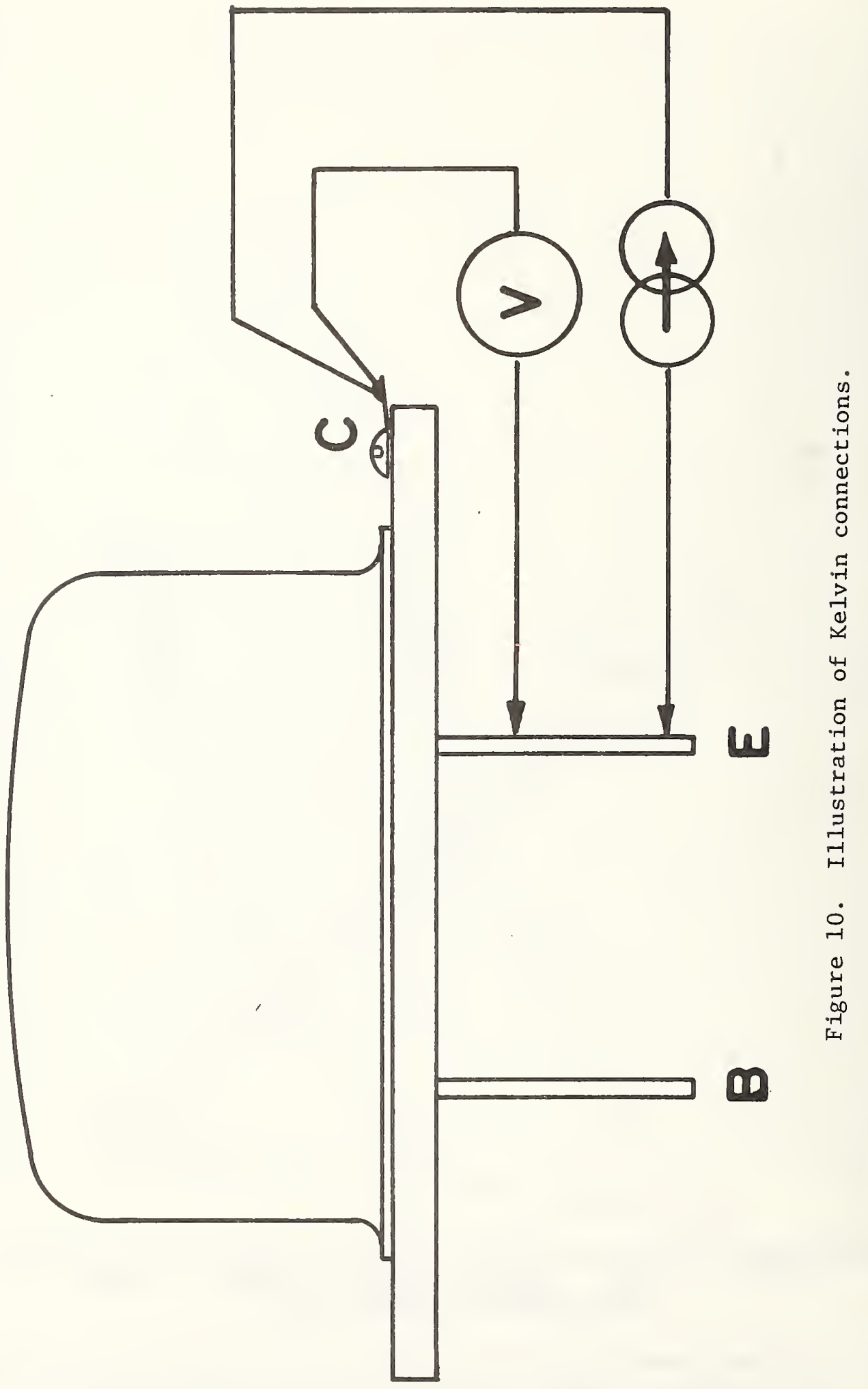


case, it is more appropriate to require their use on all transistor types.

The effect of another type of extraneous resistance is not correctable by the use of Kelvin connections. These are series resistances that occur in the circuit between the transistor and the point where the voltage sensing connection is made. The current provided by the current driving circuit will cause a voltage drop across such a resistance which will be measured by the voltage measuring circuit as part of $V_{C E}(S A T)$. An example of such a resistance is the resistance of the leads of the transistor. For this reason, the method requires that contact be made reproducibly to the transistor within $3 \mathrm{~mm}$ of the transistor case. Another source of resistance is contact resistance due to poor or dirty contacts. The method requires that the transistor holder have good quality contacts and that they be kept clean.

Another source of error in the measurement of $\mathrm{V}_{\mathrm{CE}}$ (SAT) is variations in the measurement circuit itself. The current levels used, particularly for power transistors, require considerable power dissipation in the resistors in the collector circuit. Care should be taken to select resistors that are capable of handling this power without changing resistance. In the pulsed method, a temperature drift in the resistors $R_{B}$ and $R_{C}$ could cause serious error in the measurement of $V_{C E}$ (SAT) because the measurement would be made at the wrong values of $I_{B}$ and $I_{C}$.

When the pulsed method is used, the voltage measurement of $V_{C E}$ (SAT) must be made with an instrument capable of measuring the voltage of one portion of a pulse with respect to the ground potential. See figure 3 in the method. This measurement can be made with an oscilloscope if it is capable of accurately following the pulse from the high level which occurs when the current pulse is off to the low level of $V_{C E}$ (SAT) when the current pulse is on. If, however, the amplifiers in the oscilloscope saturate, an erroneous measurement of $\mathrm{V}_{\mathrm{CE}}$ (SAT) will be made. One way to avoid this is by application of a clamping circuit at the input of the oscilloscope. The effect of this circuit is to lower the voltage during the time the current pulse is off so that it is similar in magnitude to the value of $\mathrm{V}_{\mathrm{CE}}(\mathrm{SAT})$ when the current pulse is on. An oscilloscope can easily follow the new pulse shape without saturating. An example of such a circuit is shown in Appendix X2 of the method.

A clamping circuit similar to that shown was used in the $\mathrm{V}_{\mathrm{CE}}$ (SAT) measurements described. In order to determine if the addition of the clamping circuit caused error in the measured value of $V_{C E}(S A T)$, the current was measured in the 1000- $\Omega$ resistor. It was found to be less than $1 \mu \mathrm{A}$ during the time the base current pulse was on and the $V_{C E}$ (SAT) measurement was being made. Therefore, the clamping circuit did not cause a measurable extraneous voltage drop to occur as part of $\mathrm{V}_{\mathrm{CE}}$ (SAT)

\section{SUMMARY}

A method for the measurement of $V_{C E}$ (SAT) has been outlined and discussed. It was found that the most important factor in the measurement 
of $\mathrm{V}_{\mathrm{CE}}$ (SAT) was the selection of the forced $\beta$. Precise measurement of base and collector currents is necessary. Small temperature changes are usually not important. The use of Kelvin connections to eliminate errors due to extraneous resistances is very important. Short lead lengths on the test transistors and good quality connections and contacts should be maintained. Good quality circuit components with adequate power rating should be used.

\section{ACKNOWLEDGMENT}

D. L. Blackburn, G. J. Rogers, and T. F. Leedy have provided useful comments and suggestions in the preparation of this report.

\section{REFERENCES}

1. JEDEC Recommendations for Letter Symbols, Abbreviations, Terms, and Definitions for Semiconductor Device Data Sheets and Specifications, JEDEC Publication No. 77A, p. D1 (March 1974).

2. Ebers, J. J., and Mo11, J. L., Large-Signal Behavior of Junction Transistors, Proc. IRE 42, 1761-1772 (1954). 
APPENDIX

METHODS TO MEASURE TRANSISTOR

COLLECTOR-EMITTER SATURATION VOLTAGE

\author{
Document No.: \\ Draft No.: 1 \\ Date: June 1, 1977 \\ Prepared by: K. O. Leedy \\ (301) 921-3625
}


1. Scope

1.1 These methods cover tests to determine transistor collectoremitter saturation voltage $\mathrm{V}_{\mathrm{CE}}$ (SAT) under specified conditions.

1.2 The $d-c$ method is applicable at currents low enough to produce negligible heating in the junction.

1.3 The pulse method is applicable at high currents which would cause significant heating in the junction if not pulsed.

1.4 Before this test method can be implemented, test conditions which are appropriate for the transistor type to be measured must be selected and agreed upon by the parties to the test. Conditions will vary from one transistor type to another, and are determined in part by the intended application of the transistor. The $d-c$ condition chosen should permit continuous operation of the device under test. The pulsed method should permit repetitive operation of the device under test. The following test conditions must be specified:

1.4.1 Choice of either $d-c$ or pulse method,

1.4.2 Permissible range of ambient temperature if other than nomina11y $20^{\circ} \mathrm{C}$,

1.4.3 Collector current $I_{C}$ at which the measurement is to be made, 1.4.4 Base current $I_{B}$ at which the measurement is to be made, and 1.4.5 Pulse duration and duty cycle of current pulse if other than $300 \mu \mathrm{s}$ and $2 \%$.

2. Summary of Methods

2.1 The base and collector currents of the transistor under test are each in turn adjusted to be at a specified value. The collectoremitter voltage is then measured.

3. Significance and Use

3.1 The collector-emitter saturation voltage of a transistor is a basic parameter of a transistor included in purchase specifications. The saturation voltage can be used for design purposes to predict the performance of a transistor used in saturated switching applications, such as in $d-c$ to $a-c$ power inverters, chopping circuits, and logic circuits as well as other circuits. Differences in $\mathrm{V}_{\mathrm{CE}}$ (SAT) before and after irradiation are a measure of radiation damage in the transistor. 
4. Description of Terms

4.1 collector-emitter saturation voltage - of a transistor, the voltage developed between the collector and emitter when the transistor is operated in the saturation region.

4.2 saturation region - a base-current and a collector-current condition resulting in both the emitter-base and the collector-base junction being forward biased.

\section{Interferences}

5.1 During the test, care must be taken to maintain the ambient temperature within the specified range. Deviations may invalidate test results.

5.2 Care must be taken in the selection of $I_{C}$ and $I_{B}$ for the test to assure that the transistor is operating in the saturation region. Generally, when in saturation the ratio $I_{C}$ to $I_{B}$ is less than one tenth the gain of the transistor in the active region for the same base current. If a suitable ratio is not maintained, the test results may be invalid. A method for determining if a transistor is in saturation is given in Appendix Xl.

\section{d-c Method}

\section{Apparatus}

6.1 Transistor Test Fixture - fixture to attach the transistor to be tested to the test circuit. Contacts shall be clean and of good quality. Kelvin connections shall be made to the collector and emitter leads. Electrical contact of the voltage measuring leads to collector and emitter leads shall be made to the transistor leads within $3 \mathrm{~mm}$ of the transistor case.

\subsection{Voltmeter $V_{1}$ - voltmeter with an input impedance greater} than $100 \frac{V_{C E}(S A T)}{I_{C}}$ capable of measuring $d-c$ voltage in the range of the anticipated $\mathrm{V}_{\mathrm{CE}}$ (SAT) with a full scale accuracy of $\pm 0.5 \%$ or better.

6.3 Ammeter $A_{1}-d-c$ ammeter capable of measuring current in the range of the specified base current with a full scale accuracy of $\pm 0.5 \%$ or better. 
6.4 Ammeter $\mathrm{A}_{2}$ - ammeter capable of measuring current in the range of the specified collector current with a full scale accuracy of $\pm 0.5 \%$ or better.

6.5 Voltage Sources - $d-c$ voltage sources (sources 1 and 2, Fig. 1) meeting the following specifications:

6.5.1 Stable to within $\pm 0.25 \%$ of the set voltage,

6.5.2 Noise and ripple less than $0.5 \%$ of the output voltage, and

6.5.3 Adjustable over a nominal range of zero to 30 volts.

6.6 Resistors - resistors $\left(R_{B}\right.$ and $\left.R_{C}\right)$ which meet the following requirements:

6.6.1 $R_{B}$ sha11 have a resistance of approximately $R_{B}=\frac{20}{I_{B}} \Omega$ where $I_{B}$ is the specified base current in amperes. The resistance shall be known to within $1 \%$. It shall be capable of dissipating at least $I_{B}{ }^{2} R_{B}$ watts. It shall have a temperature coefficient of resistance less than $0.1 \% /{ }^{\circ} \mathrm{C}$.

6.6.2 $R_{C}$ shall have a resistance of approximately $R_{C}=\frac{20}{I_{C}} \Omega$ where $I_{C}$ is the specified collector current in amperes. The resistance shall be known to within $1 \%$. It shall be capable of dissipating at least

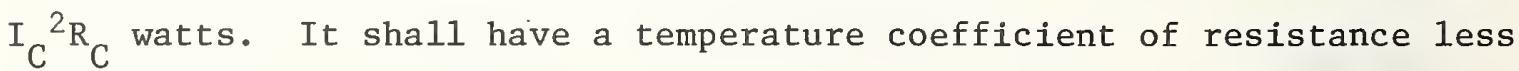
than $0.1 \% /{ }^{\circ} \mathrm{C}$.

6.7 Temperature Measuring Instrument - instrument to measure the ambient temperature with an accuracy of $\pm 2 \%$ in the range of the specified ambient temperature.

7. Sampling

This method determines the properties of a single specimen. If sampling procedures are used to select devices for test, they must be agreed upon in advance by the parties to the test.

8. Procedure

8.1 Assemble the circuit shown in Fig. 1.

8.2 Set both voltage sources at zero volts and insert transistor to be tested into transistor test fixture.

8.3 Measure and record the ambient temperature in the vicinity of the test fixture. 


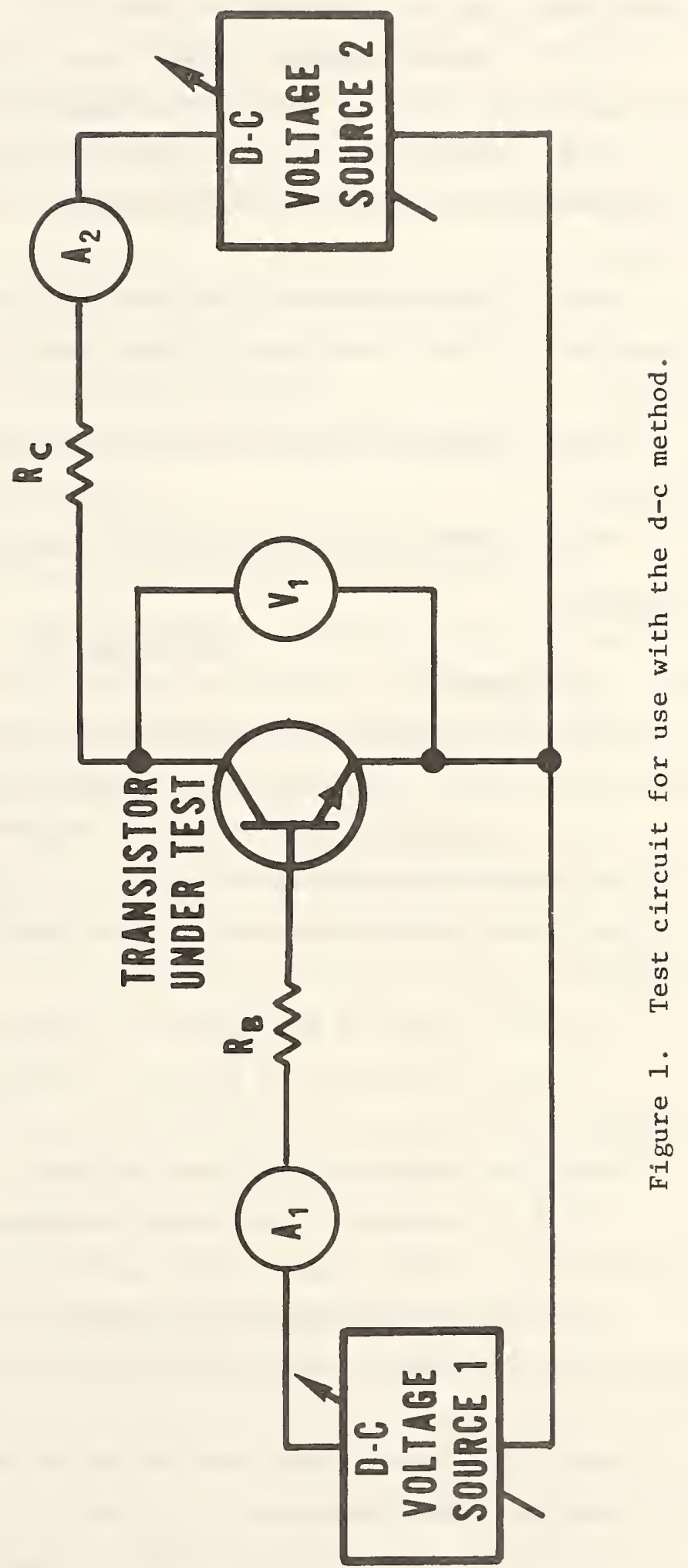


8.4 Adjust voltage source 1 until the base current equals the specified value as measured on ammeter $A_{1}$.

8.5 Adjust voltage source 2 until the collector current equals the specified value as measured on ammeter $A_{2}$.

8.6 Check ammeter $A_{1}$ to see if it still reads the specified value and, if not, readjust voltage source 1 to obtain the specified value.

8.7 Check ammeter $A_{2}$ to see if it still reads the specified value and, if not, readjust voltage source 2 to obtain the specified value.

8.8 Repeat 8.6 and 8.7 until no further readjustments are required.

8.9 Measure and record the voltage on voltmeter $\mathrm{V}_{1}$. This is $\mathrm{V}_{\mathrm{CE}(\mathrm{SAT})} \cdot$

\section{Pulse Method}

\section{Apparatus}

9.1 In addition to items $6.1,6.6,6.7$ and voltage source 2 described in 6.5, the following apparatus is required.

9.1.1 Pulsed Voltage Source - Pulsed voltage source which meets the following requirements:

9.1.1.1 Adjustable output which is sufficient to provide $I_{B}$ required,

9.1.1.2 Polarity selectable as either positive or negative,

9.1.1.3 Rise and fall times of less than 0.1 times the pulse width used,

9.1.1.4 Droop of less than 5\%, and

9.1.1.5 Capable of producing the pulse width of 300 us with a duty cycle of $2 \%$ or other pulse width and duty cycle if specified.

9.1.2 Current Measuring Equipment - equipment for measuring base current and collector current described in 9.1.2.1 and 9.1.2.2 or 9.1.2.3.

9.1.2.1 Current probe and an amplifier which used together meet the following requirements:

9.1.2.1.1 Rise time less than or equal to 0.1 times the pulse width used, 
9.1.2.1.2 Accuracy $\pm 3 \%$ or better,

9.1.2.1.3 Sensitivity of $0.1 \mathrm{~V} / A_{1}$ of better,

9.1.2.1.4 Core saturation rating exceeding the product of the current to be measured and its pulse width, and

9.1.2.1.5 Low-frequency response such that a square pulse of the width used in the test results in a negative tilt of less than $3 \%$ in the pulse interval.

9.1.2.2 Oscilloscope 1 - general-purpose laboratory oscilloscope meeting the following specification:

9.1.2.2.1 Bandwidth of $\mathrm{d}-\mathrm{c}$ to $10 \mathrm{MHz}$ minimum,

9.1.2.2.2 Input resistance greater than or equal to 100 times the resistance across which it is measuring,

9.1.2.2.3 Deflection factors covering at least the range from $5 \mathrm{mV} / \mathrm{div}$ to $1 \mathrm{~V} / \mathrm{div}$.

9.1.2.3 Osc11loscope 2 - general-purpose laboratory oscilloscope as described in 9.1.2.2 with the following additional requirements:

9.1.2.3.1 Capability of differential measurements with both inputs isolated from test circuit common, and

9.1.2.3.2 Common mode rejection ratio of $20 \mathrm{~dB}$ minimum.

9.1.3 Voltage Measuring Means - instrument for measuring and displaying the voltage waveform of nominally square pulses having the specified pulse width and duty cycle (see 9.1.1.5) and with a voltage range of zero to $20 \mathrm{~V}$.

10. Sampling

10.1 This method determines the properties of a single specimen. If sampling procedures are used to select devices for test, they must be agreed upon in advance by the parties to the test.

11. Procedure

11.1 With voltage source 2 set at zero volts, assemble the circuit shown in Fig. 2. Set the pulsed voltage source to have a pulse width of $300 \mu$ s and a duty cycle of $2 \%$ unless otherwise specified.

11.2 Insert transistor to be tested into transistor test fixture.

11.3 Measure and record the ambient temperature in the vicinity of the test fixture.

11.4 Set the base and collector currents equal to the specified 


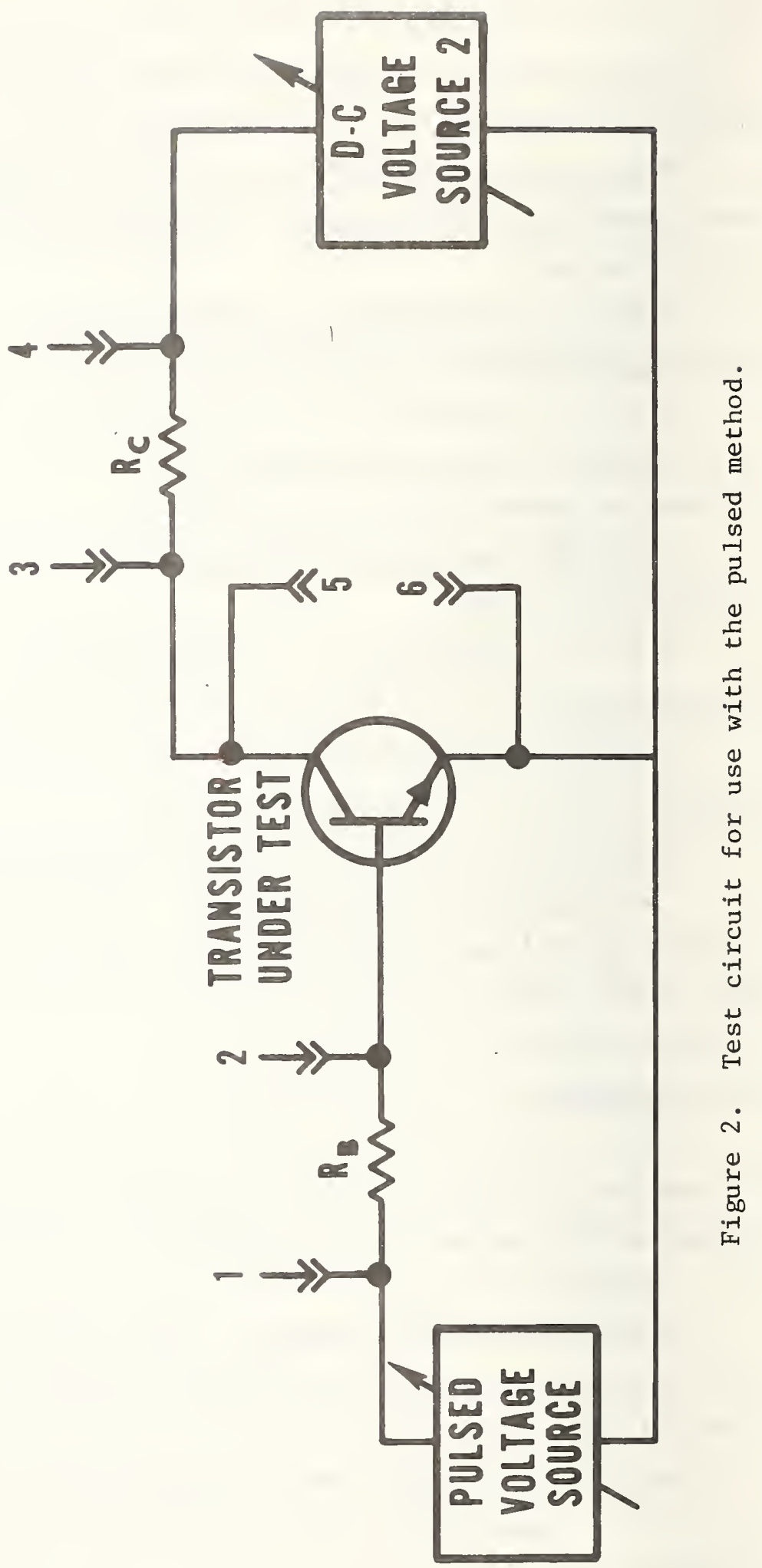


values using either $11.4: 1$ or 11.4 .2 .

11.4.1 Use a current transformer to set the base and collector currents as follows:

11.4.1.1 Attach the current probe and amplifier combination to oscilloscope 1 and position the current probe to monitor the current in $R_{B}$. 11.4.1.2 Adjust the pulsed voltage source to obtain the specified $I_{B}$.

11.4.1.3 Position the current probe to monitor the current in $R_{C}$. 11.4.1.4 Adjust the voltage source 2 to obtain the specified $I_{C}$. 11.4.1.5 Remeasure the current in $R_{B}$. If other than specified $I_{B}$, readjust the pulsed voltage source to obtain specified $I_{B}$.

11.4.1.6 Remeasure the current in $R_{C}$. If other than specified $I_{C}$, readjust voltage source 2 to obtain specified $I_{C}$.

11.4.1.7 Repeat 11.4 .1 .5 and 11.4 .1 .6 until no further readjustment is necessary.

11.4.2 Use oscilloscope 2 to set the base and collector currents as follows:

11.4.2.1 Calculate and record $V_{B}=I_{B} R_{B}$ where $I_{B}$ is the required base current.

11.4.2.2 Adjust the pulsed voltage source to obtain the required $\mathrm{V}_{\mathrm{B}}$ as measured with oscilloscope 2 connected differentially across points 1 and 2 .

11.4.2.3 Calculate and record $V_{C}=I_{C} R_{C}$ where $I_{C}$ is the required collector current.

11.4.2.4 Adjust voltage source 2 to obtain the required $V_{C}$ as measured with oscilloscope 2 connected differentially across points 3 and 4 .

11.4.2.5 Remeasure the voltage across points 1 and 2. If this is other than $V_{B}$, readjust the pulsed voltage source to obtain $V_{B}$.

11.4.2.6 Remeasure the voltage across points 3 and 4. If this is other than $\mathrm{V}_{\mathrm{C}}$, readjust voltage source 2 to obtain $\mathrm{V}_{\mathrm{C}}$.

11.4.2.7 Repeat 11.4 .2 .5 and 11.4 .2 .6 until no further readjustment is necessary.

11.5 With the voltage measuring means described in 9.1 .3 connected across points 5 and 6 , observe the voltage waveform which is similar to that shown in Fig. 3. Measure and record the voltage difference, 


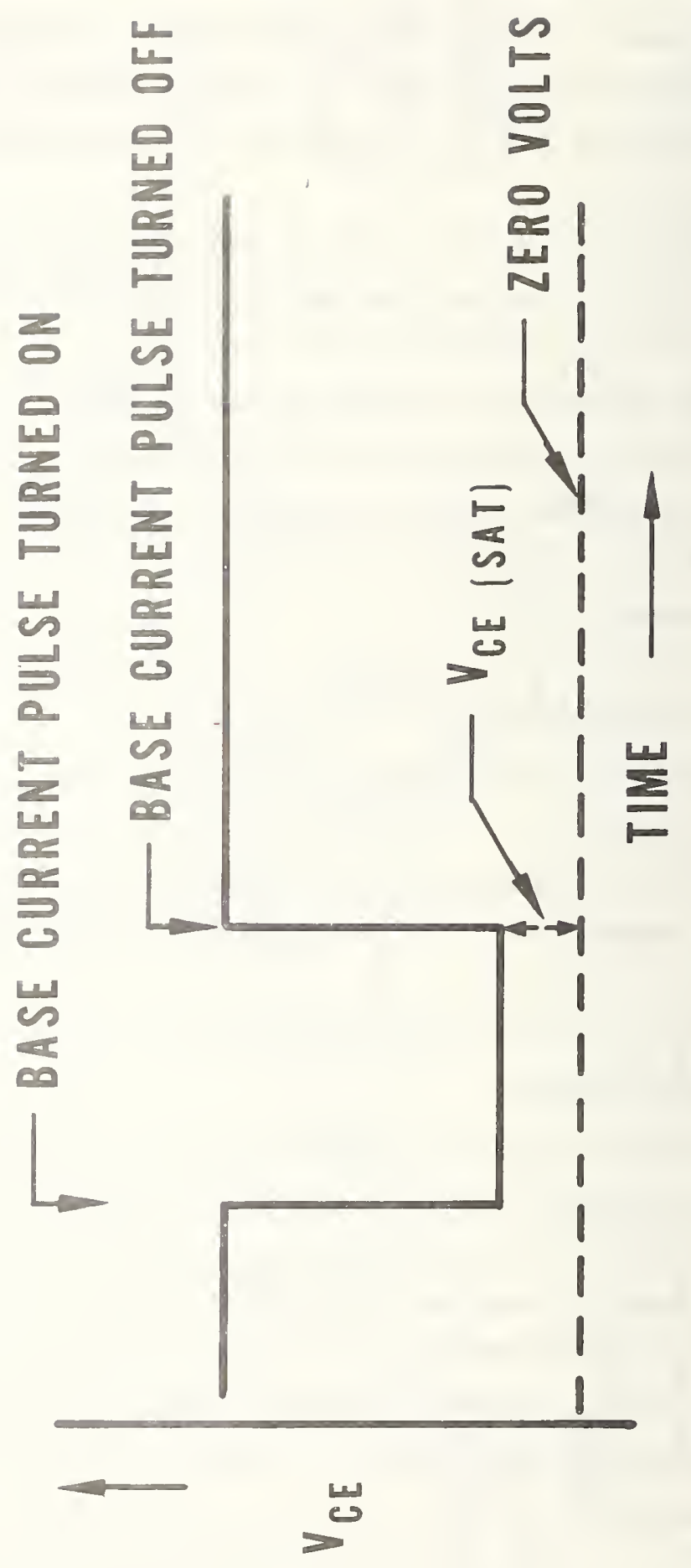

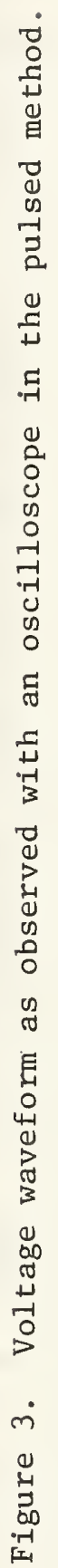


$\mathrm{V}$, indicated as $\mathrm{V}_{\mathrm{CE}}(\mathrm{SAT})$ in the figure.

Note 1 - Since the voltage difference to be measured is small compared to the pulse height, some difficulty may be encountered in making the measurement of $\mathrm{V}_{\mathrm{CE}}(\mathrm{SAT})$, depending on the detailed performance characteristics of the equipment used. Appendix X2 describes a clamping circuit which lowers the $\mathrm{V}_{\mathrm{CE}}$ pulse height and details a procedure found satisfactory for its use.

\section{Report}

12.1 The report for $d-c$ Method shall contain the following:

12.1.1 Name of person performing the test,

12.1.2 Date of the test,

12.1.3 Device type and identification of the transistor tested,

12.1.4 Ambient temperature,

12.1.5 Resistance of resistors $R_{B}$ and $R_{C}$,

12.1.6 Base and collector currents used in the test, and,

12.1.7 Measured value of the collector-emitter saturation voltage.

12.2 The report for Pulse Method shall contain the following in addition to items 12.1.1 to 12.1.7:

12.2.1 Pulse width, $\mu s$, and duty cycle, percent, and

12.2.2 Measured values of $V_{B}$ and $V_{C}$.

13. Precision

No interlaboratory precision data is available at this time. 
X1.1 In some applications it is the intention to measure the transistor collector-emitter voltage for a given bias regardless of whether the transistor is operating in the saturation region or not. However, if a measurement of the actual $\mathrm{V}_{\mathrm{CE}}$ (SAT) is required, one technique that may be used to assure that, with the specifled values of $I_{B}$ and $I_{C}$, the transistor is operating in the saturation region is to first measure $V_{C E}$ (SAT) as indicated. Then repeat the measurement with a base current equal to $2 I_{B}$. If the measured value of $\mathrm{V}_{\mathrm{CE}}$ (SAT) changes by more than $25 \%$, the transistor was not in saturation. In order to determine values of $I_{B}$ and $I_{C}$ such that the transistor is operating in the saturation region, it is necessary to plot $V_{C E}$ as a function of $I_{C} / I_{B}$ with $I_{B}$ or $I_{C}$ fixed. Sultable current values can then be chosen by looking for the flat portion of this curve. 


\section{APPENDIX X2}

$\mathrm{X} 2.1$ One technique that may be used to assist in measuring $\mathrm{V}_{\mathrm{CE}}$ (SAT) (see Note 1 ) is the use of a clamping circuit shown connected to the measuring circuit in Fig. X2.1. This clamping circuit acts to maintain the voltage across $Q_{2}$ near the anticipated level of the $V_{C E(S A T)}$ of the transistor under test. When the base-current pulse occurs, transistor $Q_{1}$ turns on which then turns off transistor $Q_{2}$. The resistor values shown are nominal. Transistors $Q_{1}$ and $Q_{2}$ can be any transistors whose $V_{C E}(S A T)$ is in the range of the $\mathrm{V}_{\mathrm{CE}}(\mathrm{SAT})$ of the transistor to be tested. It is convenient to use transistors of the same type as is being tested. With the clamping circuit connected as shown in Fig. X2.1, use the oscilloscope to measure $\mathrm{V}_{\mathrm{CE}(\mathrm{SAT})}$ and record the measured value. 


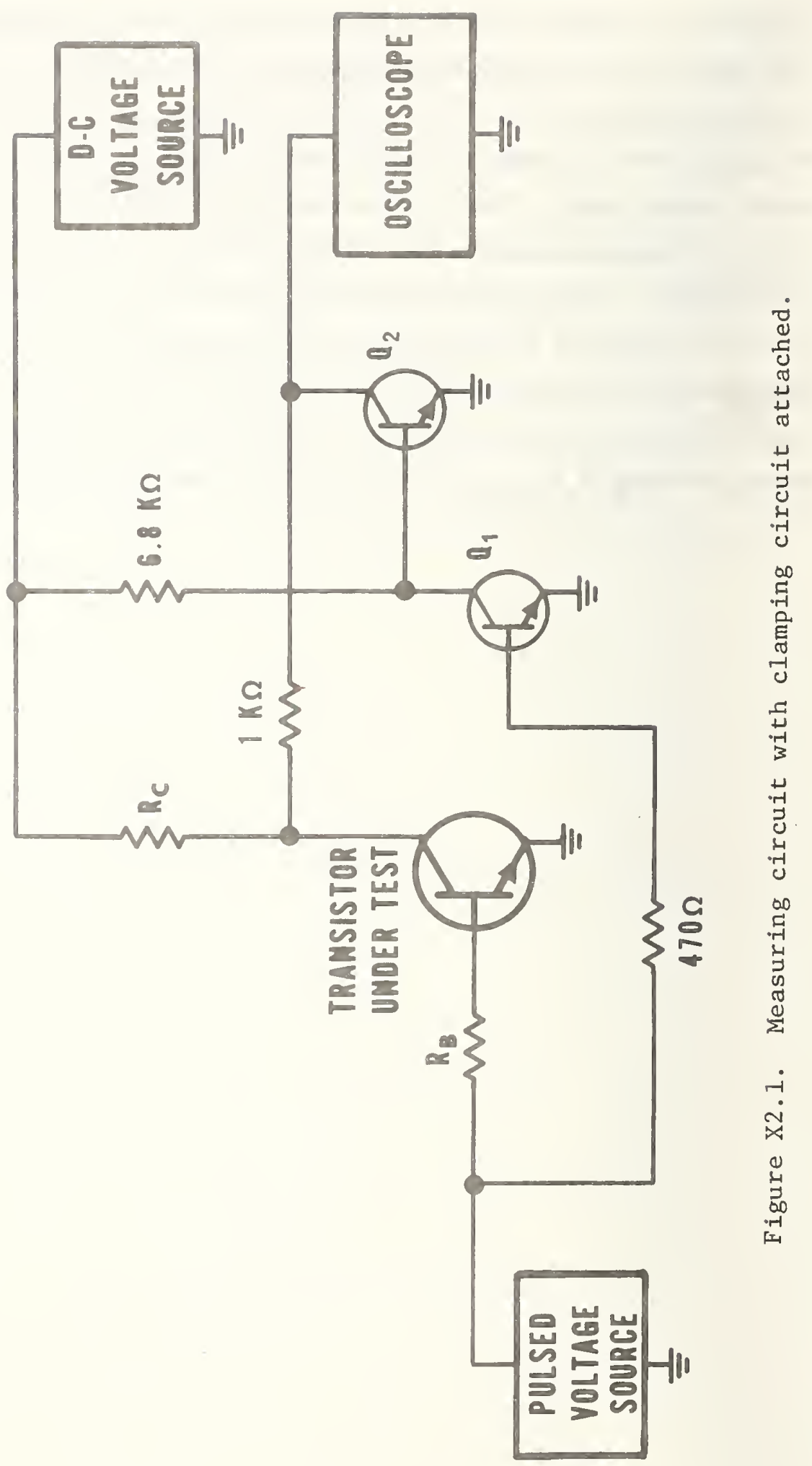


Defense Communication Engineer Center

1860 Wiehle Avenue

Reston, VA 22090

ATTN R410 James $W$. McLean

Director

Defense Communications Agency

Washington, D.C. 20305

ATTN Code 930 Monte T. Burgett, Jr.

Defense Documentation Center

Cameron Station

Alexandria, VA 22314

ATTN TC ( 12 copies)

Director

Defense Electronic Supply Center

Dayton, $\mathrm{OH} 45444$

ATTN ECS Robert E. Cooper

ATTN ECS Joseph Dennis

Director

Defense Nuclear Agency

Washington, D.C. 20305

ATTN STTL Tech Library (3 copies)

ATTN STVL

ATTN DDST

ATTN RAEV

ATTN RAEV Maj. W. Adams (2 copies)

Dir of Defense Rsch \& Engineering

Department of Defense

Washington, D.C. 20301

ATTN DDR\&E(OS)

\section{Commander}

Field Command

Defense Nuclear Agency

Kirtland AFB, NM 87115

ATTN FCPR

\section{Director}

Interservice Nuclear Weapons School

Kirtland AFB, NM 87115

ATTN Document Control

\section{Director}

Joint Strat TGT Planning Staff JCS

Offutt AFB

Omaha, NB 68113

ATTN JLTW-2

Chief

Livermore Division Fld Command DNA

Lawrence Livermore Laboratory

P.0. Box 808

Livermore, CA 94550

ATTN FCPRL
Project Manager

Army Tactical Data Systems

U.S. Army Electronics Command

Fort Monmouth, NJ 07703

ATTN Dwaine B. Huewe

Commander

BMD System Command

P.0. Box 1500

Huntsvilie, AL 35807

ATTN BDMSC-TEN Noah J. Hurst

Commander

Frankford Arsenal

Bridge and Tacony Streets

Philadelphia, PA 19137

ATTN SARFA-FCD Marvin Elnick

Commander

Harry Diamond Laboratories

2800 Powder Mill Road

Adelphi, MD 20783

ATTN DRXDO-EM R. Bostak

ATTN DRXDO-RC Robert B. Oswald, Jr.

ATTN DRXDO-EM J. W. Beilfuss

ATTN DRXDO-EM Robert E. McCoskey

ATTN DRXDO-NP Francis $N$. Wimenitz

ATTN DRXDO-RBG Joseph Halpin

ATTN DRXDO-RB Joseph R. Miletta

ATTN DRXDO-TI Tech Lib

Commanding Officer

Night Vision Laboratory

U.S. Army Electronics Command

Fort Belvoir, VA 22060

ATTN Capt. Allan S. Parker

Commiander

Picatinny Arsenal

Dover, NJ 07801

ATTN SMUPA-ND-D-E

ATTN SMUPA-ND-W

Commander

Redstone Scientific Information Ctr

U.S. Army Missile Command

Redstone Arsenal, AL 35809

ATTN Chief, Documents ( 3 copies)

Secretary of the Army

Washington, D.C. 20310

ATTN ODUSA or Daniel Willard

Commander

TRASANA

White Sands Missile Range, NM 88002

ATTN ATAA-EAC Francis N. Winans 
Chief

U.S. Army Communications Sys Agency

Fort Monmouth, NJ 07703

ATTN SCCM-AD-SV Library

\section{Commander}

U.S. Army Electronics Command

Fort Monmouth, NJ 07703

ATTN DRSEL-GG-TD W. R. Werk

ATTN DRSEL-TL-IR Edwin T. Hunter

ATTN DRSEL-PL-ENV Hans A. Bomke

Commander-in-Chief

U.S. Army Europe and Seventh Army

APO New York 09403

ATTN ODCSE-E AEAGE-PI

\section{Commander}

U.S. Army Materiel Dev \& Readiness Cmd

5001 Eisenhower Avenue

Alexandria, VA 22333

ATTN DRCDE-D Lawrence Flynn

\section{Commander}

\section{U.S. Army Missile Command}

Redstone Arsena 1, AL 35809

ATTN DRCPM-PE-EA Wallace 0. Wagner

ATTN DRCPM-LCEX Howard H. Henriksen

ATTN DRCPM-MDTI Capt. Joe A. Sims

ATTN DRSMI-RGD Victor $W$. Ruwe

ATTN AMSI-RGP Victor W. Ruwe

\section{Commander}

U.S. Army Mobility Equip R\&D Ctr

Fort Belvoir, VA 22060

ATTN STSFB-MW John W. Bond, Jr.

ATTN AMSEL-NV-SD J. H. Carter

\section{Chief}

U.S. Army Nuc and Chemical Surety Gp

Bldg. 207j, North Area

Ft. Belvoir, VA 22060

ATTN MOSG-ND Maj. Sidney W. Winslow

Commander

U.S. Army Nuclear Agency

Fort Bliss, TX 79916

ATTN ATCN-W LTC Leonard A. Sluga

Commander

U.S. Army Test and Evaluation Comd

Aberdeen Proving Ground, MD 21005

ATTN DRSTE-EL Richard I. Kolchin

ATTN DRSTE-NB Russe11 R. Galasso

\section{Commander}

White Sands Missile Range

White Sands Missile Range, NM 88002

ATTN STEWS-TE-NT Marvin P. Squires

ATTN Nuclear Effects Lab Ted F. Leura, Jr.
Commander

Naval Electronic Systems Command

Naval Electronic Systems Cmd Has

Washington, D.C. 20360

ATTN CODE 50451

ATTN ELEX 05323 Cleveland F. Watkins

ATTN CODE 504511 Charles R. Suman

ATTN PME 117-21

ATTN CODE 5032 Charles W. Neill

Director

Naval Research Laboratory

Washington, D.C. 20375

ATTN CODE 2627 Doris R. Folen

ATTN CODE 6601 E. Wolicki

ATTN CODE 5216 Harold L. Hughes

ATTN CODE 5210 John E. Davey

ATTN CODE 6620 Bruce Faraday

ATTN CODE 6627 Neal Wilsey

Commander

Naval Sea Systems Command

Navy Department

Washington, D.C. 20362

ATTN SEA-9931 Samuel A. Barham

ATTN SEA-9931 Riley B. Lane

Commander

Naval Surface Weapons Center

White Oak, Silver Spring, MD 20910

ATTN CODE WX21 Tech Lib

ATTN CODE WA50 John H. Malloy

ATTN CODE 244

ATTN CODE 431 Edwin B. Dean

ATTN CODE WA501 Navy Nuc Prgms off

ATTN CODE WA52 Fred Warnock

Commander

Naval Weapons Center

China Lake, CA 93555

ATTN CODE 533 Tech Lib

Commanding Officer

Naval Weapons Support Center

Crane, IN 47522

ATTN CODE 3073 James Ramsey

ATTN CODE 3073 Joseph A. Munarin

ATTN CODE 3073 Ron Pease

Director

Strategic Systems Project Office

Navy Department

Washington, D.C. 20376

ATTN NSP-27331 Phil Spector

ATTN NSP-2342 Richard L. Coleman

ATTN NSP-230 David Gold

ATTN SP 2701 John W. Pitsenberger 
Director

Office of Naval Research

800 N. Quincy Street

Arlington, KA 22217

ATTN 220 David Lewis

AF Aero-Propulsion Laboratory, AFSC

Wright-Patterson AFB, OH 45433

ATTN POE-2 Joseph F. Wise

AF Institute of Technology, AU

Wright-Patterson AFB, OH 45433

ATTN ENP Charles J. Bridgman

AF Materials Laboratory, AFSC

Wright-Patterson AFB, OH 45433

ATTN LTE

AF Weapons Laboratory, AFSC

Kirtland AFB, NM 87117

ATTN ELP TREE Section

ATTN ELA

ATTN SAS

ATTN ELP Capt. John G. Tucker

ATTN SAT

ATTN SAB

ATTN ELPT John Mullis.

ATTN ELPT David Ferry

AFTAC

Patrick AFB, FL 32925

ATTN TFS Maj. Marion F. Schneider

Commander

ASD

Wright-Patterson AFB, OH 45433

ATTN ASD-YH-EX LTC Robert Leverette

Headquarters

Electronic Systems Division (AFSC)

Hanscom AFB, MA 01731

ATTN DCD/SATIN IV

ATTN YSEV

ATTN YWET

Commander

Foreign Technology Division, AFSC

Wright-Patterson AFB, OH 45433

ATTN ETET Capt. Richard C. Husemann

Commander

Rome Air Development Center, AFSC

Griffiss AFB, NY 13440

ATTN RBRAC I. L. Krulac

ATTN RBRP Jack S. Smith

ATTN RBRP Clyde Lane

ATTN RBRP Joseph Brauer
SAMSO/DY

Post Office Box 93960

Worldway Postal Center

Los Angeles, CA 90009

ATTN DYS Maj. Larry A. Darda

ATTN AWSR Lt. Col. Cornelius H. McGuiness

SAMSO/IN

Post Office Box 92960

Worldway Postal Center

Los Angeles, CA 90009

ATTN IND I. J. Judy

SAMSO/MN

Norton AFB, CA 92409

ATTN MNNG Capt. David J. Strobel

ATTN MNNG

ATTN MNNH

SAMSO/RS

Post Office Box 92960

Worldway Postal Center

Los Angeles, CA 90009

ATTN RSSE LTC Kenneth L. Gilbert

SAMSO/SK

Post Office Box 92960

Worldway Postal Center

Los Angeles, CA 90009

ATTN SKF Peter H. Stadler

Commander-in-Chief

Strategic Air Command

offutt AFB, NB 68113

ATTN XPFS Maj. Brian G. Stephan

ATTN NRI-STINFO Library

University of California

Lawrence Livermore Laboratory

P.0. Box 808

Livermore, CA 94550

ATTN Tech Info Dept $L-3$

ATTN Lawrence Cleland L-156

ATTN Hans Kruger L-96

ATTN Joseph E. Keller, Jr. L-125

Los Alamos Scientific Laboratory

P.0. Box 1663

Los Alamos, NM 87545

ATTN DOC. Cont. for J. Arthur Freed

Sandia Laboratories

P.0. Box 5800

Albuquerque, NM 87115

ATTN DOC CON for 3141 Sandia Rpt Col1

ATTN DOC CON for Org $2110 \mathrm{~J}$. A. Hood

ATTN DOC CON for Org 1933 F. N. Coppage 
Department of Commerce

National Bureau of Standards

Washington, D.C. 20234

ATTN Judson C. French, A357 Tech

ATTN W. M. Bullis, A355 Tech

ATTN K. F. Galloway, A327 Tech

Aerojet Electro-Systems Co Div

Aerojet-General Corp

P.0. Box 296

Azusa, CA 91702

ATTN Thomas D. Hanscome

Aeronutronic Ford Corporation

Aerospace \& Communications Ops

Aeronutronic Div

Fort \& Jamboree Roads

Newport Beach, CA 92663

ATTN Tech Info Section

ATTN Ken C. Attinger

Aeronutronic Ford Corporation

Western Development Laboratories Div

3939 Fabian Way

Palo Alto, CA 94303

ATTN Samuel R. Crawford MS 531

Aerospace Corp

P. 0. Box 92957

Los Angeles, CA 90009

ATTN Irving M. Garfunke]

ATTN J. Benveniste

ATTN Julian Reinheimer

ATTN S. P. Bower

ATTN W. Willis

AVCO Research \& Systems Group

201 Lowel1 Street

Wilmington, MA 01887

ATTN Rosearch Lib A830, Rm 7201

The BDM Corp

1920 Aline Ave

Vienna, VA 21180

ATTN T. H. Neighbors

The Bendix Corp

Communication Division

East Joppa Road - Towson

Baltimore, MD 21204

ATTN Document Control

The Bendix Corp

Research Laboratories Div

Bendix Center

Southfield, MI 48076

ATTN Max Frank

ATTN Mgr Prgm Dev Donald J. Niehaus
The Bendix Corp

Navigation and Control Div

Teterboro, NJ 07608

ATTN George Gartner

The Boeing Company

P.0. Box 3707

Seattle, WA 98124

ATTN David L. Dye MS 87-75

ATTN Aerospace Library

ATTN Howard W. Wicklein MS 17-11

ATTN Robert. S. Caldwel1 2R-00

ATTN Carl Rosenberg 2R-00

ATTN Itsu Arimura 2R-00

Booz-Allen and Hamilton, Inc.

106 Apple Street

New Shrewsbury, NJ 07724

ATTN Raymond J. Chrisner

California Inst. of Tech.

Jet Propulsion Lab

4800 Oak Park Grove

Pasadena, CA 91103

ATTN J. Bryden

ATTN A. G. Stanley

Charles Start Draper Laboratory, Inc.

68 Albany Street

Cambridge, MA 02139

ATTN Kenneth Fertig

Computer Sciences Corp

201 La Veta Drive, N.E.

A1 buquerque, NM 87108

ATTN Richard H. Dickhaut

Cutler-Hammer, Inc.

AIL Div

Comac Road

Deer Park, NJ 11729

ATTN Central Tech Files Anne Anthony

The Dikewood Corp

1009 Bradbury Drive, S.E.

University Research Park

Al buquerque, NM 87106

ATTN L. Wayne Davis

E-Systems, Inc.

Greenville Div

P.0. Box 1056

Greenville, TX 75401

ATTN Library 8-50100

Effects Technology, Inc.

5383 Hollister Avenue

Santa Barbara, CA 93111

ATTN Edward John Steele 
Fairchild Camera and Instrument Corp 464 Ellis Street

Mountain View, CA 94040

ATTN Sec Dept for 2-233 David K. Myers

Fairchild Industries, Inc.

Sherman Fairchild Technology Ctr

20301 Century Boulevard

Germantown, MD 20767

ATTN Mgr Config Data \& Standards

Garrett Corp

P.0. Box 92248

Los Angeles, CA 90009

ATTN Robert E. Weir Dept 93-9

Genera 1 Dynamics Corp

Electronics Div Orlando Operations

P.0. Box 2566

Orlando, FL 32802

ATTN D. W. Coleman

General Electric Company

Space Division

Valley Forge Space Center

Goddard Blvd King of Prussia

P.0. Box 8555

Phitadelphia, PA 19101

ATTN Larry I. Chasen

ATTN John L. Andrews

ATTN Joseph C. Peden VFSC, Rm 4230M

General Electric Company

Re-entry \& Environmental Systems Div

P.0. Box 7722

3198 Chestnut Street

Philadelphia, PA 19101

ATTN John W. Palchefsky Jr.

ATTN Robert $V$. Benedict

General Electric Company

Ordnance Systems

100 Plastics Avenue

Pittsfield, MA 01201

ATTN Joseph J. Reid1

General Electric Company

Tempo-Center for Advanced Studies

816 State Street (P.0. Drwr QQ)

Santa Barbara, CA 93102

ATTN M. Espig

ATTN DASIAC

ATTN Royden R. Rutherford

General Electric Company

P.0. Box 1122

Syracuse, NY 13201

ATTN CSP 0-7 L. H. Dee
General Electric Company

Aircraft Engine Group

Evendale Plant

Cincinnati, $\mathrm{OH} 45215$

ATTN John A. Ellerhorst E 2

General Electric Company

Aerospace Electronics Systems

French Road

Utica. NY 13503

ATTN W. J. Patterson Drop 233

ATTN Charles M. Hewison Drop 624

General Electric Company - Tempo

ATTN: DASIAC

C/O Defense Nuclear Agency

Washington, D.C. 20305

ATTN William Alfonte

Georgia Institute of Technology

Georgia Tech Research Inst

Atlanta, GA 30332

ATTN R. Curry

Grumman Aerospace Corp

South Oyster Bay Road

Bethpage, NY 11714

ATTN Jerry Rogers Dept 533

GTE Sylvania, Inc.

Electronics Systems Grp - Eastern Div 77 A Street

Needham, MA 02194

ATTN James A. Waldon

ATTN Charles A. Thornhill Librarian

ATTN Leonard L. Blaisdell

GTE Sylvania, Inc,

189 B Street

Needham Heights, MA 02194

ATTN H \& V Group Mario A. Nurefora

ATTN Herbert A. U11man

Gulton Industries, Inc.

Engineered Magnetics Division

13041 Cerise Avenue

Hawthorne, CA 90250

ATTN Engnmagnetics Div

Harris Corp

Harris Semiconductor Div

P.0. Box 883

Melbourne, FL 32901

ATTN Wayne E. Abare MS 16-111

ATTN Carl F. Davis MS 17-220

ATTN T. L. Clark MS 4040 
Hazeltine Corp

Pulaski Road

Green Lawn, NY 11740

ATTN Tech Info Ctr M. Waite

Honeywel1 Inc.

Government and Aeronautical

Products Division

2600 Ridgeway Parkway

Minneapolis, MN 55413

ATTN Ronald R. Johnson A1622

Honeywe11 Inc.

Aerospace Division

13350 U.S. Highway 19

St. Petersburg, FL 33733

ATTN M.S. 725-J Stacey H. Graff

ATTN Harrison H. Noble M.S. 725-5A

Honeywe11 Inc.

Radiation Center

2 Forbes Road

Lexington, MA 02173

ATTN Technical Library

Hughes Aircraft Company

Centinela and Teale

Culver City, CA 90230

ATTN John B. Singletary MS 6-D133

ATTN Billy W. Campbe11 MS 6-E-110

ATTN Kenneth R. Walker MS D157

Hughes Aircraft Company

Space Systems Div

P.0. Box 92919

Los Angeles, CA 90009

ATTN Edward C. Smith MS A620

ATTN William W. Scott MS A1080

IBM Corp

Route $17 \mathrm{C}$

Owego, NY 13827

ATTN Frank Frankovsky

IIT Research Institute

10 West 35th Street

Chicago, IL 60616

ATTN Irving $N$. Mindel

Intl Tel \& Telegraph Corp.

500 Washington Avenue

Nutley, NJ 07110

ATTN Alexander T. Richardson
IRT Corp

P.0. Box 81087

San Diego, CA 92138

ATTN R. L. Mertz

ATTN Ralph H. Stah?

ATTN Leo D. Cotter

ATTN MDC

ATTN John W. Harrity

ATTN J. L. Azarewicz

JAYCOR

205 S. Whiting Street, Suite 500

Alexandria, VA 22304

ATTN Robert Sullivan

ATTN Catherine Turesko

Johns Hopkins University Applied Physics Laboratory Johns Hopkins Road

Laure1, MD 20810

ATTN Peter E. Partridge

Kaman Sciences Corp

P.0. Box 7463

Colorado Springs, CO 80933

ATTN Albert P. Bridges

ATTN Donald H. Bryce

ATTN Jerry I. Lube 11

Litton Systems, Inc.

Guidance \& Control Systems Div

5500 Canoga Avenue

Woodland Hills, CA 91364

ATTN Val J. Ashby MS 67

ATTN John P. Retzler

Lockheed Missiles \& Space Co., Inc.

P.0. Box 504

Sunnyvale, CA 94088

ATTN Benjamin T. Kimura Dept 81-14

ATTN Edwin A. Smith Dept. 85-85

ATTN Dept 81-01 G. H. Morris

ATTN L. Rossi Dept 81-64

ATTN Dept 85-85 Samual I. Taimuty

Lockheed Missiles and Space Company

3251 Hanover Street

Palo Alto, CA 94304

ATTN Tech Info Ctr D/Coll

ATTN John Crowley

LTV Aerospace Corp

Vought Systems Division

P.0. Box 6267

Dal1as, TX 75222

ATTN Technical Data Center 
LTV Aerospace Corp

Michigan Division

P.0. Box 909

Warren, MI 48090

ATTN Tech Lib

M.I.T. Lincoln Laboratory

P.0. Box 73

Lexington, MA 02173

ATTN Leona Loughlin Librarian A-082

Martin Marietta Aerospace

Orlando Division

P.0. Box 5837

Orlando, FL 32805

ATTN Mona C. Griffith Lib MP-30

ATTN Jack M. Ashford MP-537

ATTN William W. Mras MP-413

ATTN Richard Gaynor

McDonnel1 Douglas Corp

P.0. Box 516

St. Louis, MO 63166

ATTN Tech Lib

ATTN Tom Ender

Mission Research Corp

735 State Street

Santa Barbara, CA 93101

ATTN William C. Hart

Mission Research Corp-La Jolla

1150 Silverado Street

P.0. Box 1209

La Jolla, CA 92038

ATTN V. A. J. Van Lint

ATTN James Raymond

National Academy of Sciences

ATTN: National Materials Advisory Board

2101 Constitution Avenue

Washington, D.C. 20418

ATTN R. S. Shane Nat Materials Advsy

Northrop Corp

Electronic Div

1 Research Park

Palos Verdes Peninsula, CA 90273

ATTN Vincent R. Demartino

ATTN Boyce T. Ahlport

Northrop Corp

Northrop Research and Technology Ctr

3401 West Broadway

Hawthrone, CA 90250

ATTN Orlie L. Curtis, Jr.

ATTN J. R. Srour

ATTN Bavid N. Pocock
Palisades Inst. for Rsch Services, Inc.

201 Varick Street

New York, NY 10014

ATTN Records Supervisor

Power Physics Corp

542 Industrial Way West

P.0. Box 626

Eatontown, NJ 07724

ATTN Mitchell Baker

$R$ \& D Associates

P.O. Box 9695

Marina Del Rey, CA 90291

ATTN S. Clay Rogers

Raytheon Company

Hartwel1 Road

Bedford, MA 01730

ATTN Gajanan H. Joshi Radar Sys Lab

Raytheon Company

528 Boston Post Road

Sudbury, MA 01776

ATTN Harold L. Flescher

RCA Corporation

Government \& Commercial Systems

ASTRO Electronics Div

P.0. Box 800 , Locust Corner

Princeton, NJ 08540

ATTN George J. Brucker

RCA Corporation

David Sarnoff Research Ctr

W. Windsor Twp

201 Washington Road, P.0. Box 432

Princeton, NJ 08540

ATTN K. H. Zaininger

RCA Corporation

Camden Complex

Front \& Cooper Sts

Camden, NJ 08012

ATTN E. Van Keuren 13-5-2

Research Triangle Inst

P.0. Box 12194

Research Triangle Park, NC 27709

ATTN Eng Div Mayrant Simons Jr.

Rockwell International Corp

3370 Miraloma Ave

Anaheim, CA 92803

ATTN N. J. Rudie FA53

ATTN James E. Bell HAlO

ATTN George C. Messenger FB61

ATTN K. F. Hull

ATTN L. Apodaca FA53 
Rockwe 11 International Corporation 5701 West Imperial Highway

Los Angeles, CA 90009 ATTN T. B. Yates

Rockwell International Corporation Electronics Operations

Collins Radio Group

5225 C Avenue NE

Cedar Rapids, IA 52406

ATTN Alan A. Langenfeld

ATTN Dennis Sutherland

ATTN Mildred A. Blair

Sanders Associates, Inc.

95 Canal Street

Nashua, NH 03060

ATTN Moe L. Aitel NCA 1-3236

Science Applications, Inc.

P.0. Box 2351

La Jolla, CA 92038

ATTN Larry Scott

ATTN J. Robert Beyster

ATTN Victor Orphan

Simulation Physics, Inc.

41 "B" Street

Burlington, MA 01803

ATTN Roger G. Little

The Singer Company (Data Systems)

150 Totowa Road

Wayne, NJ 07470

ATTN Tech Info Ctr

Sperry Flight Systems Div

Sperry Rand Corp

P.O. Box 21111

Phoenix, AZ 85036

ATTN D. Andrew Schow

Sperry Rand Corp

Univac Div

Defense Systems Div

P.0. Box 3525 Mail Station 1931

St. PauT, MN 55101

ATTN James A. Inda MS 41T25
Stanford Research Inst

333 Ravenswood Ave

Men lo Park, CA 94025

ATTN Philip J. Dolan

Sundstrand Corp

4751 Harrison Avenue

Rockford, IL 61101

ATTN Curtis B. White

Texas Instruments, Inc.

P.0. Box 5474

Dallas, TX 75222

ATTN Donald J. Manus MS 72

TRW Systems Group

One Space Park

Redondo Beach, CA 90278

ATTN H. H. Holloway RT-2036

ATTN 0. E. Adams R1-1144 (2 copies)

ATTN R. K. Plebuch R1-2078 (2 copies)

ATTN Tech Info Center/S-1930

ATTN Robert M. Webb R1-2410

TRW Systems Group

San Bernardino Operations

P.0. Box 1310

San Bernardino, CA 92402

ATTN F. B. Fay 527/710

ATTN Earl W. ATlen

TRW Systems Group

P.0. Box 368

Clearfield, UT 84015

ATTN Donald W. Pugsley

United Technologies Corp

Hamilton Standard Div

Bradley International Airport

Windsor Locks, CT 06069

ATTN Raymond G: Giguere

Westinghouse Electric Corp

Defense and Electronic Systems Ctr

P.0. Box 1693

Friendship International Airport

Baltimore, MD 21203

ATTN Henry P. Kalapaca MS 3525

Sperry Rand Corp

Sperry Div

Sperry Gyroscope Div

Sperry Systems Management Div

Marcus Avenue

Great Neck, NY 11020

ATTN Paul Marraffino

ATTN Charles L. Craig EV 
HOJ., IAA (REV.7-73)

\begin{tabular}{|c|c|c|c|}
\hline $\begin{array}{l}\text { U.S. DEPT. OF COMM. } \\
\text { BIBLIOGRAPHIC DATA } \\
\text { SHEET }\end{array}$ & $\begin{array}{l}\text { 1. PUBLICATION OR REPORT NO. } \\
\text { NBSIR } 77-1231\end{array}$ & $\begin{array}{l}\text { 2. Gov't Accession } \\
\text { No. }\end{array}$ & 3. Recipient's Accession No. \\
\hline \multirow{2}{*}{\multicolumn{3}{|c|}{$\begin{array}{l}\text { Measurement of Transistor Collector-Emitter Saturation } \\
\text { Voltage }\end{array}$}} & $\begin{array}{l}\text { 5. Publication Date } \\
\text { June } 1977\end{array}$ \\
\hline & & & 6. Performing Organization Code \\
\hline \multicolumn{3}{|l|}{$\begin{array}{l}\text { 7. AUTHOR(S) } \\
\text { Kathryn Leedy }\end{array}$} & $\begin{array}{l}\text { 8. Performing Organ. Report No. } \\
\text { NBSIR-1231 }\end{array}$ \\
\hline \multicolumn{3}{|c|}{ 9. PERFORMING ORGANIZATION NAME AND ADDRESS } & $\begin{array}{l}\text { 10. Project/Task/Work Unit No. } \\
\text { Z99QAXTD072 W.U.66 }\end{array}$ \\
\hline \multicolumn{3}{|c|}{$\begin{array}{l}\text { NATIONAL BUREAU OF STANDARDS } \\
\text { DEPARTMENT OF COMMERCE } \\
\text { WASHINGTON, D.C. } 20234\end{array}$} & $\begin{array}{l}\text { 11. Contract/Grant No. } \\
\text { DNA IACRO 77-809 }\end{array}$ \\
\hline \multicolumn{3}{|c|}{$\begin{array}{l}\text { 12. Sponsoring Organization Name and Complete Address (Street, City, State, ZIP) } \\
\text { Defense Nuclear Agency } \\
\text { Washington, DC } 20305\end{array}$} & $\begin{array}{l}\text { 13. Type of Report \& Period } \\
\text { Covered Final } \\
\text { July } 1976 \text { to Jan. } 1977 \\
\text { 14. Sponsoring Agency Code }\end{array}$ \\
\hline
\end{tabular}

15. SUPPLEMENTARY NOTES

16. ABSTRACT (A 200-word or less factual summary of most significant information. If document includes a significant bibliography or literature survey, mention it here.)

This report presents a detailed method for the measurement of collector-emitter saturation voltage. The method which is included in the Appendix is proposed for standardization. The report also contains a description of the laboratory confirmation of the method and a discussion of the precautions to be taken to assure repeatability of the measurement. Emphasized is the necessity to determine that the conditions for saturation are met during the measurement.

17. KEY WORDS (six to twelve entries; alphabetical order; capitalize only the first letter of the first key word unless a proper name; separated by semicolons)

18. AVAILABILITY

Unlimited

For Official Distribution. Do Not Release to NTIS

Order From Sup. of Doc., U.S. Government Printing Office Washington, D.C. 20402, SD Cat. No. C13

2 Order From National Technical Information Service (NTIS) Springfield, Virginia 22151

\begin{tabular}{|l|c|}
$\begin{array}{l}\text { 19. SECURITY CLASS } \\
\text { (THIS REPURT) }\end{array}$ & 21. NO. OF PAGES \\
UNCL ASSIFIED & 54 \\
\hline $\begin{array}{l}\text { 20. SECURITY CLASS } \\
\text { (THIS PAGE) } \\
\text { UNCLASSIFIED }\end{array}$ & 22. Price \\
$\$ 4.50$ \\
\hline
\end{tabular}


